\title{
Repercusiones en Trujillo de los sucesos estudiantiles de Lima el 23 de mayo de 1923
}

\author{
Effects in Trujillo derived from student events in Lima on May 23, 1923
}

Repercussões em Trujillo dos processos estudantis de Lima de 23 de maio de 1923

\author{
Elmer Robles Ortiz ${ }^{1}$ \\ Universidad Privada Antenor Orrego (Perú) \\ Grupo de investigación HISULA - UPTC
}

Recepción: 20/05/2017

Evaluación: 10/10/2017

Aceptación: 05/01/2018

Artículo de investigación - Reflexión

DOI: https://doi.org/10.19053/01227238.8005

\section{RESUMEN}

El presente trabajo tiene el propósito de estudiar la resonancia que tuvieron en Trujillo los hechos acaecidos en Lima el 23 de mayo de 1923, dentro del movimiento estudiantil de la Reforma Universitaria iniciada en Argentina en 1918 y en el Perú en 1919. Es el resultado de una investigación que utiliza la metodología cualitativa con énfasis en el campo histórico. Los hechos ocurrieron durante el gobierno de Augusto B. Leguía que, en busca de su reelección, y violando la Constitución Política, dispuso la consagración del Perú al Corazón de Jesús. En la protesta de los estudiantes de la Universidad de San Marcos y trabajadores de Lima, reprimida violentamente, murió un estudiante y un obrero. El gobierno arrestó a los conductores del movimiento.

Estos sucesos tuvieron eco en la Universidad de Trujillo. La intransigencia del rector y del Consejo Universitario originó una fuerte tensión. Los estudiantes esbozaron conceptos a tono con los principios de la Reforma Universitaria: universidad para el cambio y de puertas abiertas como casa del pueblo y para el pueblo. Las autoridades no exhibieron ninguna postura formativa, sino compulsiva y anacrónica; respondieron con represión. Fueron expulsados definitivamente 14 estudiantes y temporalmente 8 .

Palabras clave: Universidad; reforma; estudiantes; catedráticos; autoritarismo.

1 Doctor en Ciencias de la Educación. Profesor de Historia. Licenciado en Antropología Social. Docente de pregrado y posgrado de la Universidad Privada Antenor Orrego, Trujillo, Perú. Miembro de SHELA e integrante del grupo de investigación HISULA, clasificado COLCIENCIAS categoría A de la Universidad Pedagógica y Tecnológica de Colombia. Correo electronico: ero_2502@hotmail.com 


\begin{abstract}
The present work has the purpose of studying the effects evidenced in the city of Trujillo, as a result of the events occurred on May 23, 1923 in Lima, within the student movement for the University Reform initiated in Argentina in 1918 and in Peru in 1919. It is the result of a research that uses a qualitative methodology with historical emphasis. The events occurred during the government of Augusto B. Leguía who, seeking his reelection and violating the Political Constitution, ordered the consecration of Peru to the Heart of Jesus. During the protest carried out by students of the University of San Marcos and workers of Lima, a student and a worker died as a result of the violent repression. The government arrested the movement leaders. These events were echoed at the University of Trujillo. The intransigence of the rector and the University Council created a strong tension. The students sketched concepts in accordance with the principles of the University Reform: university for change and open doors as the home of the people and for the people. The authorities did not exhibit any formative position, but compulsive and anachronistic; they responded with repression.14 students were expelled definitively and other 8, temporarily.
\end{abstract}

Keywords: University; reform; students; professors; authoritarianism.

\section{RESUMO}

O presente trabalho tem o propósito de estudar a ressonância em Trujillo dos fatos acontecidos em Lima em 23 de maio de 1923, no contexto do movimento estudantil da Reforma Universitária, iniciada na Argentina em 1918 e no Peru em 1919. É o resultado de uma pesquisa que utiliza a metodologia qualitativa com ênfase no campo histórico. Os fatos aconteceram durante o governo de Augusto B. Leguía que, em busca de sua reeleição, e violando a Constituição Política, dispôs a consagração do Peru ao Coração de Jesus. No protesto dos estudantes da Universidade São Marcos e dos trabalhadores de Lima, reprimida violentamente, morreu um estudante e um operário. $\mathrm{O}$ governo deteve os líderes do movimento.

Estes sucessos repercutiram na Universidade de Trujillo. A intransigência do reitor e do Conselho Universitário originou uma forte tensão. Os estudantes esboçaram conceitos em sintonia com os princípios da Reforma Universitária: universidade para a transformação e de portas abertas como casa do povo e para o povo. As autoridades não demonstraram nenhuma postura formativa, senão compulsiva e anacrônica: responderam com repressão. Foram expulsos definitivamente 14 estudantes e 8 temporariamente.

Palavras-chave: Universidade; reforma; estudantes; catedráticos; autoritarismo.

\section{INTRODUCCIÓN}

Dentro del proceso de la Reforma Universitaria, el primer Congreso Nacional de Estudiantes del Perú, reunido en el Cusco el año de 1920, acordó establecer Universidades Populares, cuya inauguración se realizó en Lima el 22 de enero de 1921 y en Vitarte, un pueblo de recios trabajadores cercano a la capital de la república, el 2 de febrero de ese mismo año. Según su fundador, el estudiante trujillano Víctor Raúl Haya de la Torre, que había trasladado su matrícula a la Universidad de San Marcos, dichas Universidades Populares buscaron tres objetivos: hacer obra educacional para el pueblo, redimir al Perú de la injusticia, y erigir un monumento vivo a González Prada que lo llevara a la inmortalidad. 
Entre las resoluciones del congreso mencionado se expresaba, precisamente, que estas instituciones se inspiraban en los postulados de la justicia social y deberían preocuparse por el perfeccionamiento intelectual, moral y físico del obrero.

Después se fundaron en Trujillo, Salaverry, Arequipa, Cusco, Chosica, Callao, Jauja, Ica, Puno, Huaraz, Huacho, Chiclayo y otras ciudades; se extendieron por todo el Perú. En 1922 tomaron el nombre de "Manuel González Prada".

No tenían carácter oficial ni pretendían conferir grados y títulos. Se trataba de centros de difusión cultural y capacitación técnica, sus actividades iban desde la enseñanza-aprendizaje de la lectoescritura hasta cursos de ciencias y humanidades, campañas contra la drogadicción y el alcoholismo, así como la protección del ambiente y la sensibilización por medio del arte. Sus métodos didácticos diferían de los comúnmente utilizados con niños, adolescentes o jóvenes universitarios. Eran dinámicos, adecuados a las características propias de personas que trabajaban durante el día y acudían a estudiar en horas de la noche.

A estas casas de estudios acudían obreros, artesanos, campesinos, amas de casa, trabajadores en general. Eran gratuitas. Los profesores -jóvenes estudiantes e intelectuales- lograron profundos lazos de fraternidad con sus alumnos adultos.

El presidente Augusto B. Leguía, en su afán reeleccionista, unió sus personales intereses políticos con asuntos religiosos. Amparado en el espíritu católico del pueblo y atentando contra el mandato constitucional de libertad religiosa, pretendió consagrar el Perú al Corazón de Jesús. Entonces, el 23 de mayo de 1923, estudiantes y trabajadores de Lima, convocados por la Universidad Popular, se movilizaron masivamente y defendieron con valentía la libertad de culto y de conciencia. Por la violenta represión, fueron mortalmente abatidos un estudiante de la Universidad de San Marcos y un obrero tranviario. El gobierno retrocedió. Y de inmediato inició la persecución de los directivos de la Federación de Estudiantes del Perú y profesores de la Universidad Popular. Al cabo de unos meses, Haya de la Torre, líder del movimiento, fue apresado.

La represión contra esta obra se produjo en todo el país. Cuando se inauguraron, las Universidades Populares habían recibido un voto de aplauso de la Cámara de Senadores; pero a partir de los hechos de mayo de 1923 fueron combatidas por el poder político, porque para la oligarquía y la plutocracia la educación del pueblo entrañaba riesgo. A la clausura de las Universidades Populares de Lima (1923) se unió las de otras ciudades.

Y en Trujillo, no obstante que el Concejo Provincial había acordado, en sesión extraordinaria del 24 de julio de 1923, a pedido del concejal Saniel Chavarry, premiar con medalla al Centro Universitario y a la Universidad Popular por su obra de extensión universitaria, fue clausurada en 1924, por orden del prefecto Temístocles Molina Derteano, fiel intérprete del poder autoritario. Igual suerte corrió la de Salaverry ${ }^{2}$. Cuando la ocasión les fue propicia, reanudaron sus labores, pero sujetas a las oscilaciones entre represión y fervor popular.

En los comienzos de la repercusión en Trujillo, el rector y los catedráticos expusieron su adhesión a los estudiantes y obreros de Lima y condenaron las posturas autoritarias del gobierno. Pero pronto dieron un giro de trescientos

2 Honorable Concejo Provincial de Trujillo (HCPT). Acta de sesiones 1923-1925, tomo 56, 25. 
sesenta grados cuando sus propios alumnos asumen una actitud firme frente a la represión gubernativa y formulan diversos pedidos a tono con el movimiento reformista.

Así se inició el enfrentamiento. Aquí está el inicio expreso del problema investigado.

El rector y los catedráticos, lejos de una actitud formativa, que les correspondía por su condición de tales, toman el camino de la amenaza, la compulsión y represión, que termina con la separación definitiva de unos estudiantes y la temporal de otros. Envanecidos en su estatus académico y obnubilados frente a los problemas suscitados, no escucharon a sus estudiantes ni a la sensatez de otras voces. Fenómeno parecido se ha producido en diversos momentos cuando se ha tratado de cuestiones universitarias, en particular de carácter normativo.

Planteamiento del problema. Los sucesos de Lima del 23 de mayo de 1923, repercutieron en la Universidad de La Libertad. Dicho año fue muy agitado en Trujillo, tanto en el sector estudiantil cuanto en el docente. Comenzó en este último, mediante muestras de simpatía por la actitud de los alumnos y obreros de Lima defensores de las libertades ciudadanas, y de condena al autoritarismo del gobierno de Leguía. Pero, contradictoriamente, pronto se enfrentaron a sus propios alumnos que abrazaron una posición principista frente a los mismos hechos.

Entonces, nuestro problema queda planteado en términos de dilucidar las principales manifestaciones ocurridas en Trujillo, particularmente en la Universidad de La Libertad, en tanto fueron la resonancia de los sucesos estudiantiles de Lima del 23 de mayo de 1923. Tal resonancia incluye el análisis de las actitudes y conceptos de los sectores estudiantil y docente.

\section{Objetivos}

1. Describir y analizar los hechos ocurridos en Lima el 23 de mayo de 1923, en relación con los estudiantes universitarios y trabajadores que se manifestaron en contra el autoritarismo gubernativo.

2. Describir y analizar la repercusión en Trujillo, entre autoridades, catedráticos y estudiantes, en relación con los hechos antes referidos.

3. Relacionar las ideas y actitudes de los estudiantes trujillanos con los postulados del movimiento de la Reforma Universitaria.

\section{Fundamento teórico}

Durante las primeras décadas del siglo pasado, la vida universitaria estaba envuelta en la rutina; los contenidos de aprendizaje, desvinculados de la realidad nacional; el colonialismo mental era evidente, como también las posturas de vanidad y autoritarismo; el magister dixit de los tiempos coloniales seguía en vigor. En ese contexto, las inquietudes de cambio salieron de los alumnos más que de sus catedráticos. Precisamente, la Reforma Universitaria fue obra estudiantil, no de las autoridades ni de los docentes. 
La Reforma Universitaria desde el punto de vista académico, buscó dinamizar los estudios universitarios adecuándolos a la realidad; introducir métodos activos en el proceso de enseñanza-aprendizaje; renovar y remozar la docencia; abrir la cátedra a todas las corrientes del pensamiento; promover la participación estudiantil en el gobierno universitario; alentar la investigación científica y reestructurar el aparato administrativo de la universidad. Se nutrió de los aportes del paidocentrismo de Rousseau y del pensamiento de la escuela nueva. Y desde el punto de vista social, vincular la universidad con la nación y el continente, con los problemas del país e imprimirle acento integracionista; democratizar todos los niveles de educación, no solamente el superior. Eliminó el predominio nepótico, plutocrático y oligárquico enquistado en las cátedras y órganos de gobierno de las universidades.

Mediante su acción social, realizó obra trascendente en la educación de las clases trabajadoras, no vista antes ni repetida después, especialmente a cargo de las Universidades Populares.

Con este movimiento, el Perú y los demás países de América Latina iniciaron la movilización por la búsqueda y realización de lo auténtico, de lo nuestro; la independencia cultural y la identidad nacional. Dio inspiración, nuevo rumbo y pensamiento en el orden sociocultural.

El modelo universitario reformista propugnó una universidad democrática, autónoma, integral, dinámica, social, humanista.

A lo antes dicho, agregamos que este movimiento ha legado, los postulados de comunidad universitaria, integrada por profesores, alumnos y graduados; autonomía institucional; libertad de cátedra; gratuidad de la enseñanza; participación estudiantil en el gobierno.

Predomina en el estudio de nuestra historia, sobre todo en lo concerniente a los siglos XIX y XX, el aspecto político en desmedro de los aportes de la esfera cultural.

Uno de los acontecimientos omitidos o poco estudiados es, precisamente, el concerniente al histórico movimiento de la Reforma Universitaria: sus orígenes, sus hechos principales, sus propuestas de cambio de la educación en general y no solo de las universidades, la legislación que recogió sus aportes, las instituciones académicas surgidas de su iniciativa. Y dentro de este movimiento, es omitido y hasta desconocido lo que ocurrió en Trujillo.

En diversos libros se omiten acontecimientos relevantes del siglo XX en los cuales el pueblo -trabajadores y estudiantes, por ejemplo- jugó papel descollante. Uno de dichos acontecimientos es el movimiento de la Reforma Universitaria. Sin embargo, este movimiento es el más importante en el campo de la transformación cultural y educativa de nuestro país y de toda América Latina de los tiempos contemporáneos, distinto de las asonadas que convulsionaron la agitada vida política de la república. 


\section{Importancia}

Para remozar el sistema universitario no solo habrá de considerarse el avance científico y las nuevas teorías educativas y de gestión, sino también recoger la experiencia histórica del movimiento de la Reforma Universitaria, así como escuchar a los diversos sectores involucrados en el asunto. No se trata únicamente de promover un debate entre legisladores, al fin y al cabo, entre políticos, sino en el seno de la comunidad académica.

Uno de los vacíos del sistema educativo peruano radica en la omisión de contenidos del proceso de aprendizaje del campo histórico, no obstante, la trascendencia de los acontecimientos. Entre dichos sucesos se encuentra -reiteramos- el movimiento de la Reforma Universitaria, iniciada en Córdoba, Argentina, el año de 1918 y en el Perú en 1919, y con él, hechos emblemáticos, como el Primer Congreso Nacional de Estudiantes Peruanos realizado en el Cusco en 1920 y las Universidades Populares.

Nuestra investigación es, pues, importante para las diferentes instancias del sistema educativo, incluidas las universidades, especialmente para las experiencias curriculares dedicadas al estudio de la problemática nacional y latinoamericana. Igualmente, es útil para los poderes del Estado responsables de dar las normas nacionales en materia universitaria.

Abordamos un problema desconocido en el ámbito histórico y educativo. Además de nuestro libro La Reforma Universitaria: Sus principales manifestaciones ${ }^{3}$, en el que nos referimos brevemente al problema aquí planteado, no ha sido estudiado por ningún otro autor.

\section{Metodología}

El objeto o materia que nos interesa en este trabajo es irreversible; su conocimiento es posible gracias al acopio de información escrita y al análisis correspondiente. En tal sentido, el informe utiliza los alcances de la investigación cualitativa en su modalidad de análisis de textos y asimismo usa el método histórico, por ende, pone en práctica la evaluación externa y la crítica interna del fenómeno estudiado, mediante fuentes escritas: archivos, libros y revistas.

Después de la fase heurística se hizo el análisis, la crítica histórico-educativa y la interpretación de los datos.

Hemos manejado fuentes primarias y secundarias, que nos han permitido dilucidar los hechos ocurridos en Trujillo como repercusión del movimiento del 23 de mayo de 1923 acaecido en Lima. Los datos fueron recogidos mediante fichas bibliográficas y de investigación.

3 Elmer Robles Ortiz, La Reforma Universitaria: Sus principales manifestaciones (Trujillo: Fondo Editorial de la Universidad Privada Antenor Orrego, 2009).

José Molina Bravo. "Educación pública, autonomía universitaria y cambio político: Notas para el análisis del movimiento universitario en Chile, 2011”. Revista Historia de la Educación Latinoamericana. Vol. 15 No, 21, (2013): 263 - 282. 


\section{Resultados}

23 de mayo de 1923

En 1923, el presidente de la república, Augusto B. Leguía, exteriorizó su angurria reeleccionista, disfrazándola de una aureola de religiosidad mediante la consagración del Perú al Sagrado Corazón de Jesús, hecho atentatorio en contra de la libertad de culto y de conciencia. Entonces, la Universidad Popular aglutinó un frente de lucha en defensa de ese derecho y en contra de las burdas pretensiones políticas del gobernante, que en verdad hizo suyo el anuncio de tal consagración originada en el Arzobispado de Lima. El 23 de mayo se realizó en Lima una movilización obrero-estudiantil, de cinco mil personas, aproximadamente, comandada por Haya de la Torre; en el choque con las fuerzas del orden cayeron muertos el estudiante Manuel Alarcón Vidalón, de la Universidad de San Marcos, y el obrero tranviario Salomón Ponce. Este suceso es el símbolo de la alianza que se venía gestando desde 1919 con las luchas por las ocho diarias de trabajo.

El gobierno tuvo la intención de sepultar a las víctimas sin la participación de los estudiantes y trabajadores. Pero estos, rápidamente organizados, elaboraron una estratagema para sacar los cadáveres de la morgue y conducirlos a la universidad, en medio de una enardecida muchedumbre que soportó la terrible agresión física de las fuerzas represivas, cuya caballería arremetía a sablazos y derribaba a los manifestantes, que finalmente lograron su propósito. Entonces, el velatorio se hizo en San Marcos, el día 24, en medio de fuerte estado tensional pues se filtró información sobre el asalto que perpetraría la tropa al local universitario para extraer los ataúdes, frente a lo cual los estudiantes, con el apoyo de los obreros, tomaron estrictas precauciones de seguridad, que los llevaría incluso a su inmolación mediante el incendio del edificio, que se iniciaría en la torre, al momento de producirse el ataque. El gobierno retrocedió.

El día 25 se realizó el sepelio en medio de otra multitud -calculada de 30 mil personas- que condujo los féretros desde la Universidad de San Marcos hasta el cementerio. Nunca antes en Lima se había presenciado una multitud tan grande y fervorosa como la de este cortejo fúnebre, en cuyo momento culminante el líder del movimiento pronunció un discurso utilizando significativas frases del campo religioso. En alusión a uno de los mandamientos del cristianismo repitió tres veces: "El quinto, no matar..." ${ }^{4}$. Ese mismo día, el arzobispo, monseñor Emilio Lisson Chávez, emitió un decreto mediante el cual canceló la pretendida consagración.

Impresionado por tan magno suceso, no tardará Mariátegui en escribir palabras lapidarias, reveladoras del aislamiento de los académicos respecto a su contexto social: "En el cortejo estudiantil-obrero del 25 de mayo, el rector y los catedráticos de San Marcos, que marchaban con la juventud y el pueblo, no eran

4 Felipe Cossío del Pomar, Víctor Raúl. Biografía de Haya de la Torre (México: Editorial Cultura, 1961), 203. 
sus conductores, sino sus prisioneros. No eran sus leaders, eran sus rehenes. No acaudillaban a la muchedumbre; la escoltaban. Iban llenos de aprensión, de desgano, de miedo, malcontentos y, en algunos casos, 'espeluznados'”. Entre estos personajes apáticos y timoratos figuraban el Dr. Manuel Vicente Villarán, rector, y José Matías Manzanilla, uno de los decanos. Y ampliando sus vibrantes juicios sobre el deplorable panorama universitario, encuentra falencia de maestros e ideas, no de una juventud inquieta, ávida y permeable al cambio, como la entonces agrupada en torno a la Universidad Popular: "La llanura está poblada de brotes nuevos. Únicamente las cumbres están peladas y estériles, calvas y yermas, apenas cubiertas del césped anémico de una pobre cultura académica" ${ }^{\prime \prime}$. Palabras vibrantes que desnudan la realidad sanmarquina de ese tiempo.

La oposición a la pretendida consagración no tuvo cariz anticristiano, sino de manifestación cívica en defensa de los derechos constitucionales. Aseveraciones como esta se encuentran en las propias fuentes católicas. "Si bien las intenciones del prelado eran buenas, las del dictador no podían ser calificadas de la misma manera", ha escrito Imelda Vega Centeno. Y añade: "objetivamente, la protesta del movimiento popular en 1923, no era necesariamente laicista ni anticlerical, menos aún antirreligiosa, más bien apuntaba hacia la defensa de los fueros de la iglesia católica, trastocados y utilizados en beneficio de un gobierno que estaba muy lejos de basarse en principios cristianos" 6 .

La jornada del 23 de mayo fue trascendental para la vida política del país. Según Stein, Haya de la Torre se convirtió en el personaje más popular del Perú; el líder universitario alcanzó nivel heroico. Sus conceptos los complementa con la opinión del diario El Tiempo: "Él era un héroe nacional y -más importante- a los ojos del proletariado limeño, 'el guía responsable de la clase trabajadora, de la que ya se había vuelto Maestro'. (El Tiempo. Lima, 6 de julio de 1924: 3)"77.

Después de negar su participación en tal vibrante jornada, Mariátegui valoró el suceso y escribió: “El 23 de mayo reveló el alcance social e ideológico del acercamiento de las vanguardias estudiantiles a las clases trabajadoras. En esa fecha tuvo su bautizo histórico la nueva generación [...] que entró a jugar un rol en el desarrollo mismo de nuestra historia, elevando su acción del plano de las inquietudes estudiantiles al de las reivindicaciones colectivas y sociales" ${ }^{\prime}$.

Y por su parte, Basadre anotará: “La lucha por la reforma universitaria derivó hacia la solidaridad de los estudiantes con el proletariado [...] El símbolo de ese acercamiento (1918-1924) fue, evidentemente Haya de la Torre [...] esta generación tuvo su representativo en el muchacho que creó las Universidades Populares y que comandando una densa multitud de obreros y estudiantes detuvo con su protesta callejera la consagración del Perú al Corazón de Jesús" ${ }^{\prime 9}$.

5 José Carlos Mariátegui, Temas de educación (Lima: Empresa Editora Amauta, 1970), 84.

6 José Antonio Benito Rodríguez, Emilio Lissón Chávez (Diccionario Enciclopédico de Biblia y Teología, 2016) http://www.biblia. work/diccionarios/emilio-lisson-chavez/ (9 de julio, 2016).

7 Steve Stein, “El APRA, los años de formación”, Revista Histórica VI, No. 1 (1982), 94.

8 José Carlos Mariátegui, 7 Ensayos de interpretación de la realidad peruana (Lima: Editora Amauta, 1959), 122.

9 Jorge Basadre, Perú: Problema y posibilidad (Lima: Banco Internacional del Perú, 1978), 194. 
Estos hechos encontraron eco en las juventudes estudiantiles y obreras de todo el país, que comienzan entonces a buscar su participación en las principales decisiones nacionales.

\section{La Protesta de los Catedráticos Trujillanos}

El rector Dr. Carlos E. Uceda convocó a sesión extraordinaria a la asamblea de catedráticos el 29 de mayo para que se pronunciara frente a "los graves atropellos inferidos a los universitarios y obreros de Lima el 23 del presente". Y al respecto, se presentaron tres mociones, una por el catedrático Dr. Carlos C. Godoy y dos por el propio rector. La del mencionado catedrático decía:

La Asamblea de Catedráticos de la Universidad de La Libertad, en presencia de los graves atropellos consumados en Lima contra la juventud universitaria y la población obrera de esa capital.

Acuerda:

Expresar la honda simpatía y el patriótico interés con que los miembros de la Asamblea han contemplado la actitud digna y viril asumida por la juventud universitaria de Lima frente al acto anacrónico cuya inminencia determinó esa actitud.

Condenar con justa indignación los actos de fuerza con que se ha respondido a ese noble gesto de rebeldía espiritual; $y$

Declararse en duelo durante tres días en homenaje a las nobles víctimas sacrificadas en aras del ideal.

En una moción del rector se lee:

Señor Rector de la Universidad de San Marcos

Lima.-

Los catedráticos de la Universidad de La Libertad, en asamblea de hoy, acordaron:

Protestar de los incalificables atentados de que han sido víctima los universitarios y obreros de Lima.

Solidarizarse con la Universidad Mayor en su indignación y su dolor; y declararse de duelo durante tres días.

Y la otra moción del rector es ésta:

Señor Presidente de la Asamblea Universitaria.

Lima.-Los catedráticos de la Universidad de La Libertad, en asamblea de hoy, acodaron:

Expresar su calurosa simpatía a los alumnos de la Universidad Mayor por la actitud dignísima con que han salvado el decoro nacional.

Manifestarles su anhelo porque mantengan bien alto la bandera de reforma que han desplegado; y Tributar su admiración a las nobles víctimas sacrificadas en aras del ideal. ${ }^{10}$

Por sus coincidencias, las tres contaron con la aprobación de la asamblea. Se acordó que las dos últimas fuesen telegrafiadas al rector de la Universidad de San Marcos y al presidente de la Asamblea Universitaria de Lima.

10 "Actas de Sesiones del Consejo Universitario" (Perú), Libro de Actas del Consejo Universitario de la Universidad Nacional de Trujillo 1915-1931 (CU), 343-345. 
A esta sesión asistieron: Carlos E. Uceda (rector) y los catedráticos Eleázar Boloña, Santiago Uceda, Alejandro Morales, Cecilio Cox, Saniel Chávarri, José María Fernández, Carlos C. Godoy y Julio E. Mannucci.

\section{Elección de Maestro de la Juventud}

El mes de julio de 1923, fue tenso en los medios universitarios de Trujillo. El día 9 una asamblea estudiantil dejó escuchar su voz de condena contra la represión del 23 de mayo en Lima. A raíz de ello, y como una forma de contrarrestar esa protesta, el prefecto Molina intentó organizar un Centro Universitario paralelo con el propósito de elegir Maestro de la Juventud al presidente Augusto B. Leguía, pero tan solo logró reunir a cinco adherentes. Entonces, los alumnos del verdadero Centro Universitario reaccionaron con prontitud y proclamaron al pensador mexicano José Vasconcelos, Maestro de la Juventud. Es oportuno anotar que durante las primeras décadas del siglo XX, era costumbre, entre los estudiantes universitarios otorgar ese título meritorio a una ilustre personalidad. Por aquel tiempo, Vasconcelos tenía gran audiencia en América Latina. Sus libros eran leídos por intelectuales, estudiantes y trabajadores, igualmente sus artículos, algunos de los cuales acogían los periódicos trujillanos. Desde su cargo de secretario de educación, realizaba una de las obras educativas más importantes del continente. Antes había sido rector de la Universidad Nacional Autónoma de México. La juventud latinoamericana lo consideraba un aliado en el movimiento de Reforma Universitaria.

En comunicación remitida a Vasconcelos, el egregio mexicano, la juventud universitaria trujillana, le dijo en unos pasajes: "Sentimos la urgencia de que se alce en nuestra América la gran cruzada apostólica por la libertad. Queremos que la justicia del porvenir, amasada con la sangre de nuestras entrañas, sea aquella justicia que el pasado no pudo realizar por sus limitaciones. Porque nos sentimos con capacidades para vencerlas es que comprendemos la inexorabilidad moral de nuestras responsabilidades. No queremos que nuestros hijos echen sobre nosotros el estigma de haber apagado este grito de nuestra juventud". "Los hombres como vos no pertenecen a una patria o facción de bandera, sois del mundo y para el mundo, Maestro: sois para todos aquellos que al abrir las pupilas del espíritu son capaces de reconocer y sostener la verdad". Firman: Luciano Castillo, presidente, y Salomé Díaz, secretario ${ }^{11}$.

Por su parte, Vasconcelos envío, con fecha 13 de febrero de 1924, un mensaje "A los Estudiantes de Trujillo que se dirigieron a mí en nombre de los estudiantes del Perú". En él les manifiesta, magistralmente: "Obren en grande pensando en belleza. Suelten sus fuerzas como río desbordado pero consciente de que remueve la tierra y fecunda inmensidades. Nadie podrá detener el impulso de una juventud unida y activa, generosa y libre. Usen su fuerza para derribar la

11 Castillo, Luciano y Salomé Díaz, "El gallardo mensaje de la juventud universitaria de Trujillo a Vasconcelos" Claridad. Órgano de la Juventud Libre del Perú, año 1, № 3, (1923): 15. 
tiranía del hombre, la tiranía de las instituciones y la tiranía de los propios apetitos. Y para todo esto, venzan primero en ustedes mismos, renuncien la vida dulce, para merecer la vida sublime". "La patria la encarnan sus hijos, jamás sus verdugos. Y un déspota es peor enemigo que veinte ejércitos extranjeros. La patria nada vale si no significa libertad y justicia". "Sean ustedes más firmes y más tenaces que sus enemigos; más sobrios, más laboriosos, más claros en el pensar y más resueltos en la acción y el triunfo llegará inesperado y espléndido". "Combatan la explotación del hombre por el hombre en las ciudades y en los campos, establezcan la paz que nace de la justicia y la abundancia, y una vez lograda esta victoria proscriban la violencia, condénenla y maldíganla hasta que no pueda renacer; mátenla con un derroche de bien; paguen la cárcel con libertad, el destierro con el retorno y el odio con el amor"12.

Las palabras de Vasconcelos encierran valores humanos permanentes y conceptos ajustados a la realidad peruana de entonces. Él había estado en nuestro país en 1916.

Pero, al parecer, su elección no habría caído bien en los círculos políticos. En medio de la tirantez de aquellos días, el prefecto allanó y arrebató el local del Centro Universitario, ubicado fuera de los ambientes de la universidad, entre cuyos más entusiastas alumnos figuraban Luciano Castillo (presidente), Carlos Manuel Cox, Manuel Vásquez Díaz, Edmundo Haya de la Torre, Manuel Morales Loli y Eloy Espinoza. Su presidente y otros dirigentes, comenzaron a ser perseguidos por la policía. Y el 22 de julio, aniversario de la muerte de González Prada, los estudiantes realizaron cursos de extensión universitaria en los barrios de Chicago y La Unión. Sin embargo, la policía obstaculizó esta labor educativa en beneficio de los obreros.

En estas circunstancias, los jóvenes lanzaron un vibrante manifiesto en contra del gobierno autocrático. Y el prefecto fue duramente criticado.

Inmiscuyéndose en asuntos internos de la universidad, Molina pidió al rector informara si había dado permiso a los alumnos del Centro Universitario para reunirse en el general de estudios, el día 12 de julio, cuando ya estaban impedidos de usar su antiguo local. La autoridad universitaria contestó que de esos hechos daría cuenta al Consejo Universitario. El rector también informó a este órgano gubernativo que concedió permiso al centro para una asamblea del 22 de agosto, fecha en la cual los alumnos elegirían sus delegados ante la Federación de Estudiantes del Perú, en Lima, y que emitirían su voto de honor a favor de Víctor Raúl Haya de la Torre para presidente de dicha institución. Asimismo dio a conocer que el día 23 nuevamente se reunieron los alumnos en el local universitario, acompañados de personas extrañas, a las que no identifica; esta vez, sin permiso. Dichas personas extrañas eran, indudablemente, trabajadores de la ciudad.

Frente a las actitudes represivas enrostradas por los estudiantes a la autoridad política departamental, la Municipalidad Provincial de Trujillo, representa-

12 José Vasconcelos, "Mensaje de Vasconcelos a los estudiantes peruanos" Juventud Revista de los Estudiantes Renovadores de la Universidad de La Habana I, No. VII-VIII (1924): 3-8. 
da por su Concejo, en sesión ordinaria del 7 de septiembre de 1923, acordó "un voto de desagravio al Sr. Prefecto Coronel T. Molina Derteano por la ingratitud con que han procedido los extraviados jóvenes universitarios, al declararlo enemigo del pueblo y de la juventud, de la manera más infundada"; asimismo, "protestar de este atropello moral que se pretende inferior al Señor Prefecto en su carácter de autoridad, y reconocer, por el contrario, que es el funcionario que más ha trabajado por el bienestar del pueblo y por el prestigio y adelanto de la juventud", y que "este pequeño grupo de estudiantes exaltados, están descalificados de la opinión pública y carecen de prestigio y solo se valen de este medio para la exportación como un arma de su política"13

La moción fue presentada por los concejales Elías Iturri, Manuel J. Pastor, J. Herrera Casas, J. Luis Porturas, Guillermo Roedor, Eudoro Ríos y Zoé Ganoza. Mereció aprobación unánime. Como en otras ocasiones, las autoridades ediles no hacían más que exhibir sumisión ante la prefectura. Al victimario lo presentan como víctima.

\section{Moción Estudiantil}

Por los sucesos del 23 de mayo, Víctor Raúl Haya de la Torre, fue apresado el 2 de octubre, cuando la FEP debería elegir a su nuevo presidente, cargo que pretendía por segunda vez el flamante prisionero. Como ningún candidato obtuvo los sufragios exigidos, la elección se postergó para el día siguiente, en que los delegados acordaron una fórmula unitaria y de homenaje al cautivo: Haya de la Torre, presidente; Manuel Seoane, primer vicepresidente; Pedro Muñiz, segundo vicepresidente.

Recluido en la isla de San Lorenzo, Haya de la Torre se declaró en huelga de hambre. El hecho cundió en los círculos obreros y estudiantiles. La Federación Obrera Local de Lima decretó paro general. El gobierno apresó a los dirigentes obreros y de las Universidades Populares e impuso en Lima el estado de sitio. Estudiantes y trabajadores tuvieron enfrentamientos con las fuerzas del orden. El día 9, el preso fue deportado a Panamá.

La noticia de la prisión de Haya de la Torre y del atropello a estudiantes sanmarquinos tuvieron resonancia inmediata en Trujillo. En efecto, el Centro Universitario emprendió acciones rápidas y concurrentes. Solicitó al presidente de la república ordenara la libertad del líder universitario, y en asamblea del 8 de octubre de 1923, los alumnos acordaron suspender su asistencia a clases en señal de protesta y solicitar que los señores catedráticos se adhirieran a su actitud.

La respuesta del presidente de la república, a través del prefecto del departamento fue negativa. Así lo dio a conocer el rector de la universidad en sesión extraordinaria del Consejo Universitario celebrada el 9 de octubre. A dicha sesión, presidida por el rector, Dr. Carlos E. Uceda, concurrieron los catedráticos, doctores: Francisco Quiroz Vega, Eleázar Boloña, Alejandro Morales y Ricardo

13 HCPT, op. cit., tomo 56, 41-42. 
Rivadeneira, y el secretario, doctor Ignacio Meave Seminario. En ella fueron incorporados los doctores Guillermo Eloy Espejo y Enrique Dávila Cárdenas como delegados de los alumnos, con derecho a voz y voto, de acuerdo a lo normado.

La participación de los alumnos en la administración universitaria tiene antecedentes en la edad media europea, práctica trasplantada al Perú durante la colonia. En efecto, los alumnos de la Universidad de San Marcos, a lo largo de 150 años, intervinieron, junto a sus profesores, en la elección del rector y la provisión de cátedras. En el siglo XIX, el cogobierno se redujo a la Facultad de Medicina de dicha universidad. Los Congresos Internacionales de Estudiantes celebrados en Montevideo (1908), Buenos Aires (1910) y Lima (1912) se pronunciaron por la representación de los alumnos en el gobierno universitario. El movimiento reformista iniciado en Córdoba el año de 1918 siguió esa misma dirección. En medio de la agitación estudiantil por la Reforma Universitaria en el Perú, el gobierno dictó el 20 de septiembre de 1919 el decreto que autorizó la incorporación al Consejo Universitario de San Marcos de dos delegados elegidos por los alumnos que debían ser doctores en alguna facultad. Y el 14 de octubre del mismo año, la ley № 4004 dispuso la intervención de los alumnos sanmarquinos en el nombramiento de nuevos catedráticos, para cuyo efecto debían acreditar a dos delegados al Consejo Universitario. Pronto fueron elegidos para esa función los doctores Carlos Enrique Paz Soldán y José Antonio Encinas. El primer Congreso Nacional de Estudiantes celebrado en la ciudad del Cusco en 1920 votó por la representación estudiantil ante el Consejo Universitario y en la elección del rector. Ese mismo año, la Ley de Instrucción ratificó el derecho de los alumnos a elegir sus delegados y participar en el gobierno institucional. En tal sentido, esta norma fue un triunfo del movimiento reformista.

Los primeros delegados de los estudiantes trujillanos ante el Consejo Universitario fueron los doctores Carlos C. Godoy y Marcelino Zamalloa, elegidos por sus representados en cumplimiento de lo dispuesto por la Ley Orgánica de Enseñanza (1920). Al ser incorporados en sesión del 19 de abril de 1921, el rector doctor Eleázar Boloña expresó que se complacía en tener como colaboradores en la ardua empresa de reorganizar el centro superior que conducía a personas tan preparadas, cuya designación demostraba el gran acierto los alumnos ${ }^{14}$. Terminado su periodo, hubo un tiempo intermedio en que por cuestiones de procedimiento, la delegación no se concretó.

Al declarar la incorporación de Espejo y Dávila Cárdenas ( 9 de octubre de 1923), el rector dijo que le era grato hacerlo y manifestaba su complacencia por tenerlos en el seno del consejo, pues, tal era el sentir de los miembros de este y el suyo propio, en la seguridad de que la ilustración y talento de los señores delegados serían factores eficaces en la obra común por el progreso y engrandecimiento de la universidad. Añadió que la sesión se realizaba, precisamente, a pedido de los flamantes delegados a los que concedió el uso de la palabra. En-

14 CU, op. cit., 239. 
tonces, el doctor Espejo manifestó que el objeto de la solicitud estaba contenido en la moción, suscrita por él y el doctor Dávila Cárdenas, entregada a la mesa.

Dicha moción proponía que:

a. El Consejo Universitario haga suya la protesta formulada por la asamblea de alumnos por la clausura de las Universidades Populares y la prisión del presidente de la Federación de Estudiantes del Perú, Víctor Raúl Haya de la Torre.

b. Se permita, sin limitación, el funcionamiento del Centro Universitario en uno de los ambientes de la universidad.

c. La suspensión de las labores universitarias por dos días, como manifestación de protesta por los ataques a la juventud estudiosa ${ }^{15}$.

\section{Debate de la Moción Estudiantil}

El debate giró alrededor de los tres extremos de la moción. Según Quiroz Vega, los estudiantes ya habían protestado por el arresto de Haya de la Torre, y cuya libertad fue denegada por el presidente de la república "porque en su concepto es cómplice probado en el último movimiento revolucionario que ha motivado la detención de algunos otros ciudadanos"16.

Por ello, este catedrático no encontró correcto que la universidad trujillana repitiera la misma actitud de los alumnos que la pondría en situación de rebeldía incompatible con su carácter de institución oficial. Añadió que la universidad no es un cuerpo político cuyo objeto sea formular juicios de esta clase, debe ser mesurada en hacer protestas, y atender a la ley de enseñanza; de modo que las relaciones entre el Centro de Estudiantes y los catedráticos giren en torno a lo relativo a métodos pedagógicos, programas, competencia de maestros, investigaciones científicas y otros temas culturales.

Al replicarle, Espejo -uno de los representantes de los alumnos- manifestó que la misión de la universidad no se restringía a la enseñanza, a la difusión de los conocimientos propios de las diferentes materias de cada una de las facultades, sino que era muy amplia y en la cual cabía la defensa de los principios enseñados por ella y la protesta contra el atropello de las libertades públicas, por ende, la moción presentada se hallaba dentro de las atribuciones del Consejo Universitario.

Ciertamente, la universidad no solo debe formar profesionales e investigadores distinguidos, sino ciudadanos, hombres cultos y de moral intachable. Lo cual conlleva la idea de una educación por el ejemplo. Viene a propósito citar a Antenor Orrego, un intelectual egresado de la Universidad de Trujillo, cuando escribió: "La cultura hay que vivirla en principio y vivirla en acción. No se puede, pongamos por caso, explicar y defender en el aula las llamadas garantías individuales y negarlas en la calle y en la vida cotidiana. Para el universitario -maestro o alumno- no hay término medio". Y para completar sus observacio-

15 Revista Universitaria. Órgano de la Universidad de La Libertad, año 2, No. 5 (enero-abril de 1924): 8.

16 Revista Universitaria, ibíd., (cita 15), 9. 
nes aún vigentes, este pensador añade: “No vale la pena que en los exámenes se declame de corrido el amor a la libertad, al derecho y a la justicia y en la calle se les befe y se les decapite, o por lo menos, se muestre uno diferente a sus imperativos categóricos" 17 .

Las universidades no pueden, pues, vivir al margen de la vida palpitante del pueblo, de lo contrario sus miembros serían como diablos predicadores. Nada podríamos esperar de los profesionales formados por ellas cuando viven para lucrar con su título y su trabajo, sin importarles la corrupción, la injusticia, el atropello a las libertades y la vida miserable de miles de ciudadanos. Lo cual equivale a negar los principios estudiados en las aulas. Esto no es vivir la cultura, no es proyección de la universidad a su contexto social. Es, simplemente, actitud egoísta y conformista.

En el debate, Rivadeneira dijo que todos los catedráticos conocían, perfectamente, la misión de las universidades y hasta dónde se extendía su esfera de acción, y recordó que cuando el Dr. Meave fue apresado, la gestión de la universidad para conseguir su libertad fue desoída por el gobierno, hecho que volvería a ocurrir con el consiguiente desaire para la institución.

$\mathrm{Al}$ abundar en razones, Espejo añadió que el estudiante Víctor Raúl Haya de la Torre no había tenido participación política, así lo declaraba él mismo, como también los gremios estudiantiles y obreros, hecho corroborado por su actuación de siempre; es más, había repudiado a los políticos. Por tanto, con él se cometía una grave arbitrariedad, frente a la cual cabía la protesta. Contestando al delegado de los alumnos, Quiroz Vega manifestó “que no le convencían las últimas afirmaciones que había hecho, porque después que el hombre cumple 40 años sabe, por experiencia, que no siempre las palabras están de acuerdo con los hechos"18.

Los conceptos pronunciados por Quiroz Vega eran, en verdad, ofensivos para los estudiantes, en el sentido de que estos podían decir una cosa (no hacer política), pero hacer otra, por lo tanto, no se les debía creer. Algo más se desprende de sus palabras. Él mordió su propio anzuelo, cayó atrapado por la boca, víctima de su juicio temerario: como hombre cuarentón no siempre era sincero; su experiencia personal pretendía generalizarla. Entonces, ¿por qué se le tendría que creer a él?

Por aquel tiempo, efectivamente, Haya de la Torre era un joven líder estudiantil, no político. En carta escrita en la prisión de San Lorenzo, el 3 de octubre de 1923, dirigida a los estudiantes y obreros, había criticado severamente las "intrigas de bajo imperio" fabricadas por "diversas jaurías políticas". Declaraba estar "ajeno y muy lejos de la podredumbre política nacional”. En cambio decía representar una "bandera de juventud" y agitar "las conciencias hacia la justicia”. Y añadía: “Lucho por producir la precursora revolución de los espíritus y maldigo con todo el calor de mi convencimiento a los explotadores del pueblo

17 Antenor Orrego, Obras completas. Tomo I (Lima: Editorial Pachacutec, 2011) 232. Antes, "Cultura universitaria y cultura popular", en Amauta. Año III. No 16, Lima, julio de 1928.

18 Revista Universitaria, op. cit, (cita 15), 10. 
que hacen del gobierno y la política, vil negociado culpable". "Si he de marchar al destierro, algún día he de volver. Retornaré a mi tiempo, cuando sea llegada la hora de la gran transformación"19.

Algunos años después -siendo ya ideólogo y militante político- al recordar sus años de estudiante en Lima, sus dificultades económicas y añorando su tranquilo hogar trujillano, dirá que había visto muy de cerca a "las fieras de la política peruana empujadas por su hambre a la genuflexión y al soborno, ya que el hambre de los políticos latinoamericanos es, con la del tigre, el chacal y el tiburón, la más peligrosa de las hambres, según ciertos zoólogos ${ }^{20 \prime}$.

Frente a esa situación, desde joven y en diversos momentos de su vida, Haya de la Torre expresaba su intención de limpiar la política y elevarla a su sitial realmente humano y científico. Y pensaba que la universidad metodiza y provee las armas para criticar los viejos métodos, renovarlos y ponerlos al servicio del pueblo. Además encuentra que, como actividad transversal de nuestra vida, la política tiene relación con diversos quehaceres, incluso con el arte, hecho aceptado por unos poetas, César Vallejo entre ellos, y negado por otros, como Vicente Huidobro. Por eso José Carlos Mariátegui, al reflexionar sobre este asunto escribe en 1926: "En esta, como en otras cosas, estoy naturalmente con Haya de la Torre" y añade que "la política, para Haya y para mí, que la sentimos elevada a la categoría de una religión, como dice Unamuno, es la trama misma de la Historia" 21.

En tal sentido, Haya de la Torre anhelaba que la política se orientase por una doctrina así como por valores éticos y estéticos, no por la intriga, el soborno, el hambre por los cargos públicos y la mezquindad.

Así las cosas, la protesta solicitada aludía a un alumno de la Universidad de San Marcos, exalumno de la universidad de su natal ciudad de Trujillo, y no a un político, como los corruptos rechazados por el entonces Presidente de la Federación de Estudiantes del Perú.

A su turno, Boloña dijo que la universidad no debía formular ni adherirse a ninguna protesta porque sería exponerse al desaire, en vista de que el telegrama por el cual se negaba la libertad de Haya de la Torre, encerraba el pensamiento del supremo gobierno. En cambio, propuso se remitiera un telegrama al rector de la Universidad de San Marcos significándole el sentimiento de esta Universidad por los últimos sucesos. Este pedido contó con la oposición de Meave al aducir que el gobierno ya había dado amplias satisfacciones, explicado y dado garantías a dicha institución.

En su intervención, el delegado Dávila Cárdenas dijo que por primera vez en el país se le ofrecía la ocasión de expresar sus opiniones en una universidad, pues, venía del extranjero y estaba al tanto del espíritu y orientaciones de las

19 Víctor Raúl Haya de la Torre, Obras completas Tomo I (Lima: Librería-Editorial Juan Mejía Baca, 1977). Víctor Raúl Haya de la Torre "Carta desde la prisión" en Por la emancipación de América Latina, eds. M. Gleizer (Buenos Aires: Triunvirato, 1927), 9-10.

20 Víctor Raúl Haya de la Torre, op. cit., Tomo 2. Víctor Raúl Haya de la Torre "Autobiográfica” en ¿A dónde va Indoamérica? (Buenos Aires: Editorial Ercilla, 1935), 94.

21 José Carlos Mariátegui, “Arte, revolución y decadencia”, Amauta, año I, No. 3 (1926): 23. 
universidades de Europa, y en virtud de ese conocimiento juzgaba que las relaciones entre catedráticos y alumnos debían ser más estrechas, como si aquellos fuesen los padres y estos sus hijos. Sobre esta base, pidió la adhesión y solidaridad de los catedráticos con la actitud de los alumnos a favor de Haya de la Torre, pues, no hacerlo significaba cobardía.

Frente a estas ideas, Morales mostró su desacuerdo. Sostuvo que si bien él procuraba mantener relaciones cordiales con sus alumnos, los hechos ocurridos en la Escuela de Ingenieros, en Lima, donde fueron tachados dos prestigiosos profesores (Guevara y Lisson), medida con la cual se solidarizaron los estudiantes de Trujillo sin conocimiento de causa, le llevaron a creer en puridad de verdad que las relaciones paternales o filiales entre catedráticos y alumnos era solo "un bello recurso oratorio" 22 .

El Consejo Universitario acordó que este punto pasare a dictamen de la comisión de reglamento.

\section{Universidad de Puertas Abiertas}

El delegado Espejo afirmó que la solicitud del Centro Universitario para usar, sin limitaciones, un ambiente de la institución obedecía al hecho de haberse impedido la concurrencia de miembros de organizaciones obreras y otras personas a sus sesiones. Y Dávila Cárdenas pidió la aprobación "porque según las orientaciones modernas, las universidades debían tener sus puertas abiertas para todo el mundo" 23 .

La misma idea de universidad de puertas abiertas la expondrán después estudiantes y profesores de la Universidad de San Antonio Abad, en Cusco. Allí el año de 1927, en una declaración de principios, propugnando una "universidad democrática" o "universidad de puertas abiertas", dirán que a sus aulas tendrán acceso cuantos anhelan nutrir su espíritu, adquirir conocimientos técnicos para el trabajo y la producción así como dotarle a su personalidad de fuerzas intelectuales ${ }^{24}$.

Por cierto, los jóvenes reformistas cuestionaron no solo la organización universitaria sino el orden de toda la sociedad. Fueron contestatarios, sintieron emoción social y acercáronse al pueblo. Es un error presentar al movimiento de reforma preocupado solo por la renovación del gobierno universitario, o de los métodos didácticos, o como el anhelo juvenil por realizar investigación científica. La Reforma Universitaria discurrió tanto en el plano académico o pedagógico cuanto en el campo social para mejorar las condiciones de vida de toda la población. A la misión científica, humanística y profesional de las universidades, le agregó otra importante misión: la de carácter social, mediante la cual, las altas

22 Revista Universitaria, óp. cit., (cita 15), 11.

23 Revista Universitaria, Ibid., (cita 15), 12.

24 Herrera, Fortunato L. y otros, "Bases para reformar la Universidad del Cuzco. Ante Proyecto de un Nuevo Estatuto Universitario" Amauta, Año II, No. 10, (1927). El documento es suscrito, además de Herrera, por José Gabriel Cossío, Luis E. Valcárcel, J. Uriel García, Leandro Pareja, Alberto Araníbar P., J. S. García Rodríguez, 52. 
casas del saber deberían estudiar los problemas nacionales y buscar sus soluciones, ponerse al alcance de los grupos menos favorecidos económicamente y proyectar su labor cultural al pueblo. Los reformistas plantearon y practicaron la proyección social y extensión universitaria, cuyos medios fueron, entre otros: las universidades populares; el acceso libre de los interesados a las clases, bibliotecas, laboratorios, museos y archivos; la publicación de revistas y folletos; cursos, conferencias y otros eventos para el público; el asesoramiento a gremios de trabajadores. El primer Congreso Nacional de Estudiantes (1920), inspirado en los postulados de justicia social, dio vida a las universidades populares, inauguradas en 1921, para educar a obreros, campesinos, artesanos, amas de casa, empleados...mediante cursos y otras actividades de cultura general y técnica, en busca del perfeccionamiento intelectual, moral y físico de los trabajadores, así como en la defensa de sus derechos.

Es decir, las universidades fueron entendidas por la juventud reformista como instituciones de puertas abiertas, no cerradas o enclaustradas a manera de conventos; casas de cultura para el pueblo, no solo formadoras de profesionales.

Los alumnos al requerir de un ambiente para su organismo gremial, donde se reuniesen y recibiesen a trabajadores y otros ciudadanos, estaban en una posición a tono con las ideas y prácticas que se abrían en el mundo. Los conceptos de su delegado, doctor Dávila Cárdenas, fueron acertados y son ahora practicados por las universidades públicas y privadas.

El rector manifestó que "el Consejo Universitario, espontáneamente, había cedido uno de los departamentos de la Universidad para que el Centro Universitario celebrara sus sesiones en vista de que carecía de local ${ }^{25 \prime}$.

En sesión del Consejo Universitario del 28 de agosto, el rector ya había informado que el presidente del mencionado organismo estudiantil solicitó permiso para reunirse en asamblea en ambientes universitarios por haber sido privados de su antiguo local, ubicado fuera de las instalaciones de la universidad. En aquellos días, algunos estudiantes estaban en condición de perseguidos por la autoridad política por los sucesos del mes de julio, considerados opuestos al gobierno. En la referida sesión, Meave sostuvo que por la solidaridad que se debe guardar entre maestros y alumnos creía procedente permitir sus reuniones dentro del establecimiento universitario, mientras encontraban un local aparente. Opiniones similares emitieron Morales y Boloña. Entonces, el Consejo Universitario acordó: "Consentir que el Centro Universitario sesione en uno de los salones de clase de la Universidad, debiendo el presidente de dicha institución recabar, en su oportunidad, el permiso respectivo del Rectorado; que en las sesiones se trate únicamente de asuntos estudiantiles y que a ellas no tengan acceso personas extrañas"26.

Pero en la sesión del 9 de octubre, el doctor Quiroz Vega se opuso al segundo punto de la moción presentada por los delegados de los alumnos, sosteniendo

25 Revista Universitaria, op. cit., (cita 15), 12.

26 CU, op. cit., 361-362. 
que el uso del local tenía limitaciones; le señaló condiciones: permiso otorgado por el rector, circunscribir las sesiones a fines estudiantiles y la exclusiva concurrencia de alumnos a ellas. Entonces, el pedido de los alumnos fue desestimado por todos los votos, menos los de sus delegados.

Este hecho nos pone al frente de un concepto reduccionista. El uso de un aula para las reuniones del Centro Universitario no era considerado un derecho, sino una concesión, convertida en un favor, a los alumnos, vistos como personas ajenas a la universidad, restringida a institución solo de profesores que, arbitrariamente, someten a parámetros anacrónicos y encasillan los anhelos juveniles de opinar sobre la marcha de su propia casa de estudios, y de compartir inquietudes renovadoras con el pueblo. Los catedráticos actuaban como dueños de la universidad que, por ser del Estado, le pertenece a todos.

El público trujillano se enteró de estos acuerdos mediante la publicación del acta por los diarios, en uno de los cuales, El Norte, Antenor Orrego, su director, exalumno universitario, escribió el editorial el 12 de octubre en uno de cuyos párrafos se lee: “El criterio de que la Universidad está constituida, únicamente por el profesorado, revela un concepto petrificado de la enseñanza. La Universidad no se ha hecho para mantener catedráticos, sino para enseñar alumnos. Son estos, pues, la materia viva, la materia moldeable, el cuerpo y el alma necesarios". "El profesorado con respecto a la Universidad, no es sino el elemento burocrático, es decir, el elemento que debe prestar servicios a trueque de una paga o emolumento. La sustancia viva o receptora es el alumnado". "El dómine, dictador escolar que asumía todos los poderes, es una simple curiosidad arqueológica dentro de la pedagogía moderna" ${ }^{27}$.

Qué avanzadas las ideas antes expuestas y qué lejos estaban los catedráticos trujillanos del pensamiento paidocentrista de Juan Jacobo Rousseau, que impregna todas las teorías pedagógicas contemporáneas. Los alumnos -hoy nadie lo niega- son el centro y eje, la razón de ser de las instituciones educativas.

Ideas similares a las de Orrego se escucharon por toda América Latina antes y después de los sucesos de Trujillo. En los primeros documentos producidos por los reformistas de Córdoba ya se hablaba de "república universitaria" conformada por profesores, alumnos y egresados. Gabriel del Mazo, el adalid reformista de Argentina, había sostenido que los alumnos, pulso vital de la institución, son el pueblo en las aulas. Y los estudiantes de La Plata, expresaban: “Los modernos sistemas pedagógicos, derivan su eficacia de la educación del consorcio de alumnos y profesores. El clásico rigor del magíster ha sido suplantado por el consejo persuasivo, y el respeto a las autoridades se funda, no en la fiereza de las medidas que se impongan, sino en el temple de la propia integridad moral" ${ }^{\prime 28}$. En Chile, los estudiantes mediante un manifiesto de 1922, usando terminología democrática, hablaban de pueblo universitario. "Llamamos -decían- pueblo

27 Antenor Orrego, Obras completas, op. Cit, Tomo II, 254-255. Antes, "El conflicto universitario", El Norte, 1930, en el cual su autor transcribe el editorial de 1923 del mismo periódico acerca de los sucesos universitarios de entonces.

28 Gabriel Del Mazo, "Memorial de la Federación Universitaria al Ministro de Instrucción Pública fundamentando su pedido de intervención a los fines de la reforma institucional y reorganización de la Universidad. La Plata, 26 de noviembre de 1919" en La Reforma Universitaria Tomo II, (Lima: Universidad Nacional Mayor de San Marcos, 1968), 112. 
universitario al conjunto de alumnos que son la vida, el medio, el espíritu de la Universidad; de profesores y de los profesionales que conservan vínculos con la Universidad, que nosotros llamados los egresados" ${ }^{\prime 2}$. En Brasil, Juan A. Mesplé dirá después: "No habiendo en la Universidad problemas ajenos a los intereses de los alumnos ¿cómo tolerar la existencia de asuntos de cuyo conocimiento sean deliberadamente excluidos los estudiantes?" Y considera que la participación de ellos en el gobierno universitario "constituye el elemento más indicado para combatir el retrógrado espíritu del feudalismo en el magisterio, que considera la Universidad como una propiedad privada de los profesores, donde se satisfacen vanidades y se contemplan ambiciones" ${ }^{\prime 30}$. Y más tarde, un rector reformista, salido de las canteras del movimiento estudiantil de su país, Carlos Martínez Durand, dirá desde Guatemala: “Debe partirse siempre del que aprende, es decir, centrar la universidad en el estudiante. El estudiante es el pueblo en las aulas. Profesores, graduados y alumnos, en ósmosis de cultura, en reciprocidad educativa, forman la Universidad, auténtica república de estudiantes, de estudiosos de toda categoría y edad" ${ }^{\prime 3}$.

Baste esta muestra del ideario de la Reforma Universitaria para demostrar que la conjunción de profesores y alumnos le imprimen a la universidad sentido de integración comunitaria de sus miembros. Entonces, no se podía negar a los alumnos su derecho de juzgar las actividades realizadas en su institución. No solo criticar el servicio educativo, la eficacia o ineficacia de los métodos didácticos, sino presentar sugerencias y aportes a la administración de la universidad. Con la Reforma, el estudiante, de elemento pasivo y cumplidor de obligaciones, dentro de un marco a veces de falsa disciplina, pasa a ser activo y consciente protagonista de la marcha de su casa de estudios.

Pero los catedráticos de Trujillo de 1923 aún no entendían así los asuntos universitarios.

\section{Suspensión de Labores}

En este punto, el catedrático Quiroz Vega expresó que los alumnos ya habían proclamado y ejecutado el paro de sus actividades durante dos días, y que el Consejo Universitario no estaba constituido para refrendar los actos estudiantiles sin esperar su decisión. En tal virtud opinó que fuera desechado, como efecto ocurrió con todos los votos excepto de los representantes de los alumnos.

Y así la Universidad de La Libertad guardó silencio.

La protesta y suspensión de labores no solo era por el encarcelamiento de Haya de la Torre, sino también "por los ataques a la juventud estudiosa", como

29 Eugenio González y otros, "Los ideales de la revolución universitaria en Chile" en La Reforma Universitaria, op. cit., t. II, 69. El manifiesto está fechado en Santiago, el 3 de julio de 1922. Los resaltados son nuestros, ERO.

30 Juan Mesplé, "La Reforma Universitaria en Río Grande del Sur" en La Reforma Universitaria, op. cit., tomo II, 212. Discurso pronunciado en Porto Alegre en 1934. Los resaltados son nuestros, ERO.

31 Carlos Martínez Durand, "La Reforma Universitaria en Guatemala" en La Reforma Universitaria, op. cit., tomo II, 367. Fragmento de discurso de 1950. Los resaltados son nuestros, ERO. 
reza la moción. Lo cual alude a la represión y agresión sufrida por los estudiantes sanmarquinos, uno de los cuales cayó abatido. Igualmente incluía la clausura de las Universidades Populares incluida en la moción.

\section{La Universidad, casa del pueblo y para el pueblo}

La falta de ponderación y la intolerancia de los profesores agravaron la situación y desencadenaron nuevos hechos. La prohibición a los estudiantes de sesionar en el local de la universidad no fue tenida en cuenta. El Centro Universitario se reunió en asamblea, tomó acuerdos y los dio a conocer a través de los diarios. El 10 de octubre, 26 alumnos sesionaron en los ambientes de la institución y discutieron los acuerdos adoptados por el Consejo Universitario el día anterior. Y tomaron sus propios acuerdos que, resumidos, son los siguientes:

a. Condenar y extrañar la actitud de tres catedráticos: Francisco Quiroz Vega, por sus demostraciones antiestudiantiles en el seno del Consejo Universitario, al expresarse con "frases despectivas sobre la viril y sincera actitud de la juventud" al manifestar que si bien los alumnos podían declarar que no participaban en política, una cosa eran las palabras y otra los hechos; Ricardo Rivadeneira, "por la insólita manera en que se refirió a una exposición del doctor Enrique Dávila Cárdenas", sobre las relaciones afectivas entre catedráticos y alumnos; y Alejandro Morales, por su "anacrónico criterio" respecto a la tacha de catedráticos incompetentes.

b. El criterio de varios catedráticos no se avenía con las disposiciones de la ley de enseñanza. Además, el reglamento vigente era anacrónico, anterior a dicha ley y, por lo mismo, no podía ser tenido en consideración.

c. La actitud de los alumnos al solicitar a los catedráticos apoyo moral en los difíciles momentos por los que atraviesa la juventud estudiosa, no buscaba formar un gremio con ellos, sino estrecharse más en una comunidad de ideas y sentimientos.

d. Los estudiantes consideran a "la Universidad como la casa del pueblo y para el pueblo" y la casta de hombres acaparadores del saber es opuesta a los nuevos sentimientos de profusión del conocimiento.

e. Se impone una reforma universitaria que marque las verdaderas atribuciones de profesores y alumnos según las nuevas normas de vida ${ }^{32}$.

f. Un estudiante disintió de los acuerdos y pidió que su opinión constara en el acta.

Entre los conceptos vertidos en tales acuerdos, merece destacar los que consideran a la universidad como casa del pueblo y para el pueblo. Esto es, una institución que, cumpliendo su misión social, proyecta su saber hacia la población de su entorno; una institución de puertas abiertas, como ya se ha comentado en párrafos anteriores. Ideas semejantes o coincidentes surgieron en diversos países latinoamericanos en el proceso de la Reforma Universitaria. En la Universidad de Trujillo, su rector Antenor Orrego, ubicado en esta línea, expresará en 1947 que

32 Revista Universitaria, op. cit., (cita 15), 21-22. 
la universidad debía extender los beneficios de la cultura a toda la población, volcar su saber hacia su contexto social "porque la Universidad es, y así debe ser, la Institución máxima de los hijos del pueblo"33. Estas evidencias demuestran que los jóvenes trujillanos no caían en el egoísmo de preocuparse solo por ellos; no querían que la universidad formase una casta de hombres acaparadores del saber. Todo lo contrario, anhelaban una universidad al servicio del pueblo no solo de un grupo elitista, privilegiado, favorecido por la fortuna, que acudía a sus aulas para lograr un título profesional. Y por eso quieren una reforma universitaria. Reforma que no se quedaría reducida al entredicho de estudiantes y profesores, dentro de los ambientes exclusivamente universitarios, sino que saliera a la realidad circundante a confundirse con el pueblo. "La Reforma Universitaria -escribió Haya de la Torre en 1925- corría riesgo de perder su sentido social, su misión precursora y gloriosa si quedaba como un simple movimiento universitario encaminado a preparar mejor, bajo más apropiadas condiciones, al profesional. Yo he entendido siempre la Reforma Universitaria como todo lo contrario al refinamiento de un sistema que creara mejor, es decir, más definida y más fuerte, una casta profesional". Por eso pensaba en la conversión del profesional en un "obrero intelectual", tender a la universidad social y educar al estudiante en contacto con los trabajadores ${ }^{34}$.

Para que la reforma abra la universidad al pueblo, los estudiantes trujillanos querían que las relaciones con sus profesores sean las entonces propaladas por el movimiento: relaciones cordiales, según las nuevas normas de la vida universitaria, no autoritarias.

\section{Complicación: Moción Disciplinaria}

Frente a estos hechos, el Consejo Universitario en sesión extraordinaria realizada el día 14 de octubre, tuvo una reacción que, lejos de buscar la concordia, complicó las relaciones con los estudiantes. Parecía que ciertos catedráticos hubiesen desenvainado sus espadas. Los cated ráticos Francisco Quiroz Vega y Ricardo Rivadeneira, ambos censurados por la asamblea estudiantil -como queda dicho- presentaron una moción disciplinaria, en cuyos considerados aducen que:

- Es incompatible la concesión hecha por la universidad al Centro Universitario de un departamento para la celebración de sus sesiones, con la actitud de 25 estudiantes, quienes tergiversando los conceptos emitidos en el Consejo Universitario, han condenado y extrañado la opinión de tres catedráticos, en forma irrespetuosa.

- La improbación hecha es ajena a la función del Centro Universitario y atentatoria al régimen institucional y al prestigio de la Universidad.

Por eso propusieron:

33 Antenor Orrego, Memoria del Sr. Dr. don Antenor Orrego, rector de la Universidad Nacional de Trujillo, leída el día de la apertura del presente año académico (Trujillo: Librería e Imprenta Moreno, 1947), 36.

34 Haya de la Torre, Obras completas Tomo 1, (Lima: Librería-Editorial Juan Mejía Baca). Haya de la Torre, Por la emancipación de América Latina, op. cit., 126-127. 
- Suspender la concesión hecha al Centro Universitario en sesión del 23 de agosto del uso del local.

- Llamar al orden a los 25 alumnos firmantes del acta de improbación para que mantengan sus derechos dentro de los límites establecidos por la ley de enseñanza, apercibiéndoles de expulsión en caso de reincidencia.

El delegado Espejo manifestó que los alumnos no habían tenido intención de ofender a los catedráticos Rivadeneira, Quiroz Vega y Morales, a quienes respetan, sino que los términos de sus acuerdos solo significaban diversidad de conceptos. Por su parte, el delegado Dávila Cárdenas, oponiéndose a la moción, dijo que era contraria a las nuevas orientaciones pedagógicas, que su severidad era excesiva y cuya aprobación significaría un abuso de la mayoría del Consejo Universitario puesto que "los catedráticos hacían el papel de patrones que botan de su casa a los sirvientes" 35 .

Defendiendo su propuesta, Quiroz Vega sostuvo que si bien la tolerancia era buena, no siempre merecía el aplauso, pues "hay tolerancias culpables" como las de "los maestros que disimulan lo que deben corregir, faltando a su deber de educar". Y agregó: “Que la moción, a pesar de su severidad, está animada en un espíritu amplio y generoso; pues no lleva consigo ningún mal directo a los estudiantes, individualmente considerados; reduciéndose a suspender el servicio del local que se les cedió espontáneamente para que sesionasen en corporación, por el exceso en que habían incurrido y a llamarlos al orden, con la prevención consiguiente" ${ }^{36}$. Además sostuvo que, en cumplimiento de un estricto deber, esto era lo menos que podía hacer el Consejo Universitario, para lograr de los alumnos el alto ejemplo de moralidad, cultura y severidad en el cumplimiento de sus obligaciones.

Como se ve, este docente confunde generosidad con amenaza. Los términos más utilizados en el debate aludían a falta de consideración y respeto por parte de los estudiantes, agravios de estos, severidad, corrección, orden, moralidad, cargos y falsedades. Uno de ellos, Morales, dijo que los delegados no habían presentado satisfacciones al Consejo Universitario en nombre de los alumnos, tampoco desautorizado o retirado los términos contenidos en los acuerdos publicados. Otro, Rivadeneira, al comentar la conducta de los estudiantes afirmó que en lo sucesivo ya no les tendrá las consideraciones de antes, "porque si alguna lección le habían dado los alumnos, era la de que estaban demás con ellos las consideraciones personales y los vínculos sociales que siempre se había complacido en cultivar", y que ni él ni sus compañeros catedráticos eran retrasados pedagogos universitarios, pues, era autor de muchas iniciativas, expuestas en el Consejo Universitario, de "las más avanzadas reformas universitarias que hoy son, solamente una aspiración para las primeras universidades del mundo" y que la nueva ley de instrucción dejó sin efecto ${ }^{37}$. No dijo cuáles eran dichas reformas.

35 Revista Universitaria, op. cit., (cita 15), 18.

36 Revista Universitaria, Ibid., (cita 15), 18.

37 Revista Universitaria, óp. cit., (cita 15), 19. 
Aprobada la moción disciplinaria, con la oposición de los delegados, se discutieron los dictámenes de la comisión de reglamento recaídos en la solicitud de protesta por la captura de Haya de la Torre y la clausura de las Universidades Populares, alcanzada en la sesión del día 9 de octubre. El dictamen en mayoría, suscrito por Santiago E. Uceda (hermano del rector), Carlos Vega y Sanabria, y Cecilio Cox, se pronunció porque no sea discutida la protesta formulada por la asamblea de estudiantes, mientras estos, por el prestigio de la universidad, el respeto a sus profesores y la estima propia de cada alumno, no retirasen los conceptos desfavorables a los doctores Quiroz Vega, Rivadeneira y Morales. Y en su dictamen en minoría, Guillermo E. Espejo opinó que, sin tomar en cuenta los acuerdos a posteriori de los estudiantes, el Consejo Universitario confirme con su actitud moral las lecciones teóricas sobre el respeto a la libertad individual y de pensamiento así como a la Carta Fundamental del Estado.

Fue aprobado el dictamen en mayoría por todos los votos, menos los de los delegados. Vale decir, la Universidad, institución por esencia deliberante, creadora y comunicadora de ideas, prefirió la mudez a decir su palabra sobre los hechos estudiantiles acaecidos en Lima. Y esto no obstante que el catedrático Quiroz Vega había sostenido, en la sesión anterior que la universidad "debe ser mesurada en hacer protestas" ${ }^{38}$. No se trataba, obviamente, de proferir ofensas a nadie, mediante una protesta con términos reñidos al comportamiento de una casa de estudios. El pedido de los alumnos, a través de sus delegados, implicaba una protesta moderada, con el tono grave propio de una institución académica. Pero los docentes optaron por el silencio. Al parecer, el doctor Quiroz Vega olvidó sus palabras que abrían la posibilidad de una protesta alturada.

\section{El Derecho de los alumnos a reunirse en el local de su Universidad y la expulsión temporal}

Las medidas de disciplina no surtieron efecto. Las sesiones de los estudiantes prosiguieron en las aulas de la universidad. El 18 de octubre, el presidente del Centro Universitario, Luciano Castillo, dio cuenta a la asamblea del oficio remitido por el rector, Carlos E. Uceda, que transcribía el acuerdo del Consejo Universitario de suspensión del uso del local y la llamada al orden a 25 alumnos, bajo apercibimiento de expulsión en caso de reincidencia. En su respuesta, el Centro Universitario afirma que en la reprobación a tres de sus profesores no ha existido otro ánimo que el de exponer un concepto nuevo y puro, sin embargo, de su actitud se ha hecho una cuestión de disciplina donde solo existe una discrepancia de ideas. Y anuncia al rector que "los estudiantes también hemos acordado sostener el derecho que nos asiste para realizar asambleas en el local de la Universidad, derecho que está reconocido en la práctica de todos los insti-

38 Revista Universitaria, Ibid., (cita 15), 9. 
tutos superiores de enseñanza". A continuación, el oficio del Centro Universitario, dice en forma tajante: "La Universidad no es, ni puede estar constituida por el profesorado, el estudiantado la integra y ambos tienen igual derecho de vivir en ella su vida plena de actividad; por eso es que la juventud no estima como una concesión, sino como un derecho, la realización de sus actos sociales en el local de la Universidad"39. La comunicación está suscrita por Luciano Castillo, presidente, y Salomé Díaz, secretario.

Las razones expuestas por los estudiantes sobre sus derechos y la conformación de la universidad por ellos y los profesores, como ya se ha visto, son valederas, principios defendidos por el movimiento reformista. $Y$ vigentes en nuestros días.

Pero para el rector y su Consejo Universitario se trata de desacato a sus órdenes. Así se lee en el acta de la sesión extraordinaria celebrada por dicho órgano de gobierno el 19 de octubre, no obstante que el presidente del Centro Universitario, con oficio de esa fecha, pide a los miembros del Consejo Universitario contemplen con visión de maestros el momento que vive la juventud de Trujillo. Y el delegado Espejo pide se reconsidere la suspensión de la concesión hecha a los alumnos del uso del local de la universidad para sus sesiones sin ninguna limitación. Pero este pedido fue desechado por tener solo tres votos a su favor. El rector puso a debate el apercibimiento contra los 15 estudiantes que, según sus palabras, habían asumido una actitud de desacato e indisciplina.

Los delegados de los alumnos, Espejo y Dávila Cárdenas opinaron que el caso fuese contemplado por la asamblea de catedráticos por su carácter extraordinario. Tanto el rector como los profesores Quiroz Vega y Rivadeneira, adujeron que dicha petición era contraria a la Ley Orgánica de Enseñanza. Entonces, ambos delegados se retiraron de la sesión.

Luego en el debate, las intervenciones de Quiroz Vega y Rivadeneira enfatizaron en que los 15 alumnos no habían acatado las expresas prohibiciones de sesionar en los ambientes universitarios; que habían desconocido la potestad gubernativa del consejo y perturbado el orden y la disciplina, cuyo restablecimiento implica hacer efectivo el apercibimiento. El catedrático Morales fue moderado, sostuvo que las faltas cometidas eran resultado de la impremeditación y exageración juveniles, por ende, las medidas a tomar no debían ser de carácter definitivo, sino que bastaba la separación temporal de los 15 alumnos. Y así, por unanimidad de votos, se acordó la expulsión de dichos alumnos hasta el 31 de marzo de 1924, bajo apercibimiento de acordarla definitiva en caso de reincidencia.

Dichos alumnos fueron: Luciano Castillo, Carlos M. Cox Roose, Manuel Morales Loli, Demetrio Cedrón Camacho, Manuel Vásquez Díaz, Enrique Benites Loayza, Carlos M. Porras, Teodomiro Sánchez, José Salomé Díaz, Fernando L. Chávez, Jaime W. Calderón, Isaac Deza Chávarri, Manuel Antonio Villacorta, Edmundo Haya de la Torre y César Alva Castillo.

39 Revista Universitaria, Ibid., (cita 15), 25 - 26. 
A los pocos días, un grupo de alumnos presentó un memorial por el cual solicitaban al rector convoque a una asamblea de catedráticos, a cuyo conocimiento y resolución se someta el acuerdo del Consejo Universitario que impuso la pena de expulsión a 15 alumnos. En sesión extraordinaria del 2 de noviembre, dicho órgano de gobierno mandó al archivo el referido memorial porque sus actos no eran pasibles de revisión. Igualmente fue desechada, por extemporánea, la solicitud de reconsideración del presidente de la Federación de Estudiantes del Perú. El catedrático Ignacio Meave dijo que la situación creada en la universidad no tenía ningún cariz político ni de otra bandería, de modo que la actitud represiva asumida por el Consejo Universitario fue para salvar la disciplina, a fin de que no se sentara el funesto precedente de ejercer gobierno con el criterio de la vocinglería y la muchedumbre. El delegado de los alumnos, Guillermo E. Espejo solicitó la remisión de la pena impuesta a los alumnos expulsados, alegando que el origen de los sucesos estaba en la actitud estudiantil de protesta frente a la prisión de Haya de la Torre, con quien se solidarizaban, en gesto digno de aplauso, sus compañeros del Centro Universitario pero que se dejaron llevar por su apasionamiento y entusiasmo juveniles al usar el local, cuya concesión les fuera retirada, para dar a conocer precisamente ese acuerdo del Consejo Universitario, hecho disculpable en jóvenes llenos de ideales. Quiroz Vega dijo que la universidad, en defensa de sus respetos, suspendió el uso del local concedido, al Centro Universitario, en cuyo nombre se había hecho la improbación de tres docentes; asimismo que se llamó al orden a los 25 estudiantes firmantes del acta y que por ser universitarios no se los podía recluir ni amonestar como a escolares, por ello, la pena no debía ser otra que la expulsión, y que esta había sido acordada con carácter temporal, pero en atención de las circunstancias, estaba de acuerdo con la suspensión de la medida.

Tergiversando las palabras de Espejo, en el sentido de que los alumnos retiraban los conceptos vertidos en contra de tres profesores y que sus actos no significaban desobediencia a la autoridad del consejo, este acordó unánimemente la remisión de la pena de expulsión a los que no desautorizaren a sus delegados. Casi al terminar la sesión llegó un telegrama del ministro de instrucción, Ego Aguirre, por el cual pedía la reconsideración del acuerdo de separación de los alumnos. Ante este hecho, el Consejo Universitario autorizó al rector contestara al ministro informándole el acuerdo tomado. En efecto, mediante telegrama, se le comunicó que los delegados de los alumnos habían retirado los conceptos publicados en contra de los catedráticos y que acataban la disciplina y decisiones del consejo, razón por la cual este levantó la pena de expulsión.

Pronto surgieron discrepancias en relación con los términos empleados en el debate y en el acuerdo registrado en acta, hecho que agravó la situación. En la siguiente sesión extraordinaria del 15 de noviembre, Espejo expresó que dicha acta era conforme, excepto en la parte en la cual aparece el retiro de los conceptos vertidos por los alumnos en contra de tres catedráticos, pues él se concre- 
tó a ratificar sus declaraciones y protestas que en las sesiones anteriores había formulado sobre el respeto y consideración de los alumnos a sus profesores. Y el delegado Dávila Cárdenas expresó conceptos similares. En el acta se habían anotado, pues, conceptos distorsionados de la representación estudiantil. El acta de la sesión anterior fue aprobada por todos los votos, menos los de los señores delegados. El doctor Fernández dijo que habiendo sido ratificada el acta por abrumadora mayoría, la remisión de la pena impuesta a 15 alumnos quedaba vigente, pero por haberse producido la retractación de los delegados, pidió que se acuerde exigir a los alumnos expulsados una declaración de que estaban resueltos de acogerse a ese beneficio, por los fundamentos que determinaron dicha remisión, es decir, el retiro de términos de condena contra sus profesores y aceptación del orden y disciplina dispuesto por el Consejo Universitario. Llamado urgentemente, el doctor Alejandro Morales abandonó la sala; la sesión fue suspendida. Reabierta el día siguiente, el rector puso a discusión el pedido del doctor Fernández, quien al hacer nuevamente uso de la palabra manifestó que acababa de leer en los periódicos declaraciones de los estudiantes según las cuales el conflicto seguía en pie, y que de esto se iba formando un embrollo mayor por las contradicciones de dichos e interpretaciones de conceptos, y van cambiando las cosas de una sesión a otra, de modo que pedía la aprobación de su pedido. En efecto, fue aprobado con la oposición del delegado Espejo en lo concerniente a la declaración de los alumnos que quisieran acogerse al perdón. En otras palabras, se pretendía someter a los alumnos a la genuflexión. Así mismo se aprobó, por los mismos votos, el tenor del telegrama de respuesta dirigido por el rector al ministro de instrucción. El delegado Dávila Cárdenas no asistió a esta continuación de la sesión.

\section{El conflicto está en pie}

Después de la sesión antes descrita, hubo asamblea de estudiantes convocada por el Centro Universitario y en ella se tomaron diversos acuerdos:

a. Retiro de la delegación ante del Consejo Universitario, como manifestación de protesta.

b. Vacancia del rectorado por incapacidad de quien lo desempeña.

c. Tacha a los catedráticos: Carlos E. Uceda (rector), Ignacio Meave, José María Fernández, Ricardo Rivadeneira y Francisco Quiroz Vega, por inmoralidad. Los alumnos de la Facultad de Letras, fundamentando su decisión, expresaron que durante el año, el catedrático de filosofía, Rivadeneira, había asistido solo una vez a clase.

d. Declaratoria de huelga estudiantil.

e. Reclamo de acción solidaria a los estudiantes de Lima, Arequipa y Cusco con el movimiento universitario trujillano.

A esta reunión asistió un grupo de obreros que habían protestado por el despojo del local donde funcionaba la Universidad Popular de Lima. Se adhirieron 
a los acuerdos de los estudiantes e hicieron presente que la causa de la juventud era suya.

El diario El Norte publicó la información que antecede en su edición del 17 de noviembre. Y con fecha 19 del mismo mes, 26 alumnos enviaron un memorial a los catedráticos neutrales, en cuyas primeras líneas se lee: “Llevados por nuestro concepto, enseñado por vosotros en las cátedras, de que el supremo poder reside en los electores, que lo delegan en representantes que pueden, por razón de las circunstancias, perder la confianza en la entidad representada: en nombre de este derecho reconocido por todas las leyes e inscrito en la conciencia colectiva, apelamos a vosotros pidiendo intervengáis en este conflicto, que a prolongarse irá en desmedro no solo de las partes beligerantes, sino de la Universidad como ser corporativo" ${ }^{40}$. Luego manifestaron que la responsabilidad de toda la situación recae directamente en el rector, Carlos E. Uceda, por su ineptitud o debilidad para defender los fueros de la institución. El conflicto, decían, estaba virtualmente terminado, pero recrudeció por falta de tino del rector al transmitir al ministro de instrucción un telegrama que consignaba hechos falsos, tan es así que no se atrevió a comunicar su contenido por los diarios de Trujillo, sino a los de Lima, pues no hubo retractación de los alumnos a través de sus delegados; consideraban a dicho telegrama -al tenor del cual aparecían en actitud claudicante- como el origen de la nueva situación e inoportuno. Asimismo informaban que solicitaron personalmente la renuncia del doctor Uceda para terminar con el bochornoso escándalo, pero él se refugió en la ley "como si alguna hubiera que tratara de impedir a los hombres enmendar sus yerros y evitar los daños". Refiriéndose al rector, agregan: "Suya pues será la culpa, si llevados por nuestra exaltación produjéramos actos de violencia, que a pesar de nuestras buenas determinaciones, acaso no podamos evitar". Y pedían a los catedráticos neutrales sus opiniones y les dijeron que el solo hecho de reunirse sería una muestra de amor hacia sus alumnos y hacia la universidad que aman, por ser parte de su vida y fuente de tantas inquietudes ${ }^{41}$. Los diarios El Norte y La Industria publicaron el memorial.

Pero no hubo ninguna respuesta. Por el contrario, un grupo de seis catedráticos comunicó, en la misma fecha, su adhesión al rector y al Consejo Universitario por su empeño en el mantenimiento del orden y la disciplina. Ellos fueron: P. A. Lizarzaburu, Santiago E. Uceda (hermano del rector), Julio E. Mannucci, C. Vega y Sanabria, Víctor A. Hernández y E. L. Albrecht. La Industria publicó el oficio de los adherentes.

Con esta adhesión, no había esperanzas de una pronta solución. El conflicto seguía en pie. Los bandos parecían irreconciliables. La suerte estaba echada en una universidad polarizada.

40 Revista Universitaria, op. cit., (cita 15), 46.

41 Revista Universitaria, op. cit., (cita 15), 48. 


\section{Expulsión temporal y definitiva}

Así fue. El conflicto se agudizó. Los profesores perdieron la serenidad, buena consejera en la toma de decisiones. En sesión extraordinaria del 20 de noviembre, el rector, Carlos E. Uceda, dio cuenta al Consejo Universitario de "graves sucesos ocurridos dentro del claustro, los cuales constituían nuevos ataques a la disciplina y a la moral de la Universidad". Los informes fueron dos: a) Ese día, la puerta de calle de la universidad fue trancada con mesas y bancas, sacadas de las aulas, y en las paredes existían letreros, pero no dio a conocer qué decían. b) Encontrándose en la Prefectura, a las 11 de la mañana -a donde acudió a informar a la autoridad política de que en memorial publicado por un periódico los alumnos amenazaban "practicar actos de violencia"- ante el aviso dado por un policía de la perpetración en el local universitario de grave falta de hecho por parte de un alumno contra un catedrático, de inmediato, "se constituyó el señor Prefecto, en compañía del señor Rector en la Universidad, donde comprobó que el exalumno don Carlos M. Cox había agredido al Dr. Rivadeneira" ${ }^{42}$.

Como se ve, a Cox se le considera exalumno, antes de producirse la votación por la cual se acordó su expulsión definitiva.

Mientras Meave decía que él vio al alumno Cox golpear a Rivadeneira, a consecuencia de lo cual cayó al suelo, éste (Rivadeneira), solicitado por el primero a declarar "francamente lo que había pasado", expuso: "que él no acusaba a nadie particularmente; que el grupo de alumnos, del cual había salido la agresión de que fue víctima, había estado en uno de los claustros hablando y riendo bulliciosamente, mientras él conversaba en el claustro próximo. Como disimulara esto, comenzaron a silbar y después a cantar, y que al hacerles presente él la obligación en que estaban de guardar compostura, había sido víctima de un ataque tan sorpresivo que no pudo ni siquiera defenderse. Que en su concepto la agresión fue resultado de un acuerdo anterior hecho ostensible, sin recato, por publicaciones y actitudes provocadoras, y que, por consiguiente, el hecho fue colectivo" $^{\prime 3}$. El catedrático agredido, Rivadeneira, negó, pues, en el momento, en forma tajante, la afirmación de Meave, cuando este sindicó al estudiante Cox como agresor.

Los consejeros Fernández y Quiroz Vega dijeron que, ante la gravedad de la situación, la solución consistía en la expulsión de todos los alumnos participantes en tales hechos. Por su parte, Boloña deploró profundamente lo sucedido, lo cual se acentuaba ante la cercanía de la conmemoración del centenario de la universidad en que la armonía institucional era indispensable. Además dijo que, por ser pariente cercano del alumno Carlos M. Cox, se abstenía de intervenir en el debate y en la votación.

A esta sesión no asistieron los delegados de los alumnos, porque fueron retirados por el Centro Universitario, según acuerdo del 16 de noviembre, como

42 Revista Universitaria, Ibid., 51.

43 Revista Universitaria, Ibid., 51-52. 
manifestación de protesta por la actuación del Consejo Universitario en el tratamiento dado al conflicto, acusado de haber distorsionado las expresiones de los doctores Espejo y Dávila Cárdenas.

El rector, para la aplicación de la pena a que se habían hecho acreedores, distinguió dos clases de alumnos: a) los reincidentes de indisciplina, y b) los que últimamente se habían adherido a los anteriores en publicaciones, así como en actos de desacato y desorden.

Puesta al voto la cuestión, fueron expulsados definitivamente por todos los votos menos el de Boloña (que se abstuvo), los alumnos reincidentes: Luciano Castillo, Carlos M. Cox, Manuel Morales Loli, Demetrio Cedrón, Manuel Vásquez Díaz, Carlos M. Porras, Teodomiro Sánchez, José Salomé Díaz, Fernando L. Chávez, Jaime W. Calderón, Isaac Deza Chavarri, Manuel Antonio Villacorta, Edmundo Haya de la Torre (hermano de Víctor Raúl, el adalid del movimiento estudiantil en Lima) y César Alva Castillo.

Y expulsados temporalmente, por el año académico en curso (1923, cuyo término estaba fijado para el 31 de marzo de 1924): Eloy Espinoza, Arturo Goicochea de la Reguera, José C. La Cunza, Víctor A. Rodríguez Porturas, Teófilo A. Cruz, Ricardo Ramos Gamboa, Luis González, Diógenes M. Vásquez, Enrique Rodríguez Lizarzaburu, Pedro Lizarzaburu, Alberto Moreno y Ramón G. Ferrer.

El primer grupo lo conformaban 14 alumnos; el segundo 12. De este, Enrique Rodríguez Lizarzaburu, Pedro Lizarzaburu, Alberto Moreno y Ramón G. Ferrer, presentaron recursos en los cuales manifestaron que sus nombres fueron indebidamente incluidos, sin su consentimiento, en el memorial publicado por los periódicos, por cuya razón el Consejo Universitario les levantó la pena, en sesión del 25 de noviembre.

Entre los estudiantes que sufrieron el arbitrario castigo figuraron tres miembros destacados del célebre Grupo Norte: Carlos Manuel Cox, Manuel Vásquez Díaz y Eloy Espinoza.

A la sanción impuesta por la institución académica, la autoridad política pretendió sumar otra. Al día siguiente del acuerdo, el prefecto, Temístocles Molina Derteano, notificó a los estudiantes expulsados para que en el plazo de ocho días abandonaran la ciudad. Pero la rápida reacción de los trabajadores trujillanos impidió este nuevo atropello. El mencionado Molina era conocido por su autoritarismo, él había dirigido la masacre de trabadores cañaveleros del Valle de Chicama, en años anteriores, y reprimido a los dirigentes de sus organizaciones gremiales, además amedrentaba a periodistas ubicados en el lado de la justicia social. Siguió de cerca los hechos estudiantiles y también quiso imponer su castigo. Pero esta vez no le fue posible.

El rector informó, el 26 de noviembre, al ministro de instrucción, Ego Aguirre, -entre otros asuntos- el desarrollo de los hechos, desde la presentación de la moción por los delegados de los alumnos, vista en la sesión del 9 de octubre, hasta la sesión del 25 de noviembre en que dejó sin efecto la expulsión temporal de 4 alumnos. Allí le dice al ministro, en relación a las tachas de los catedráticos dadas a conocer por los alumnos con fecha 16 de noviembre, que fueron acorda- 
das bajo la influencia de la pena de expulsión temporal y que solo dos de ellas, fundadas en incompetencia pedagógica, han sido presentadas al Rectorado por el presidente y secretario del Centro Universitario, ambos expulsados, y las demás solo fueron comunicadas al público por los periódicos.

Pero con la misma simplicidad de la lógica del rector, también se podría decir lo contrario: la expulsión temporal fue acordada porque los alumnos, en asamblea del 10 de octubre, expresaron su voto de condena y extrañamiento a tres profesores por su actuación contraria a los estudiantes en el Consejo Universitario. Vale decir, la expulsión era una represalia.

Asimismo informa el rector que los alumnos no han presentado ninguna divergencia de criterios pedagógicos con sus profesores, ni nuevas orientaciones sobre enseñanza, "ni han iniciado reforma alguna"; se trata única y exclusivamente de actos de lamentable rebeldía ${ }^{44}$.

Un análisis de los documentos de ambas posiciones nos presenta, en el lado de los alumnos y sus delegados, algunas ideas avanzadas, aunque brevemente expuestas, sobre educación universitaria, como ya hemos comentado; en cambio, en el lado del Consejo Universitario, no se encuentra ninguna de tales ideas, pues, el énfasis está puesto en medidas disciplinarias y represivas. Y si de iniciar una reforma se trataba, el peso favorable también se inclina hacia los estudiantes porque con sus ideas, actitudes y manifestaciones en defensa de principios, dieron sus aportes en el largo proceso del movimiento universitario reformista. $Y$ al contrario, el platillo de la balanza de los profesores queda vacío. Algo más, en este contexto, "iniciar una reforma" -conceptos del rector- no es lo mismo que iniciar o protagonizar un movimiento por la reforma. Este implica un rumbo-de corto o largo alcance- a seguir que puede concretarse en un tiempo indeterminado o quedarse solo en el plano de las intenciones, como una esperanza, tal caso de los estudiantes trujillanos. En cambio, dar inicio a una reforma implica tomar decisiones de ejecutarla y llevarla a término, es un acto administrativo, incumbencia de las autoridades, no de los estudiantes. Y como se ve, el rector no acogió ninguna idea de los estudiantes; las ahogó, menos tomó decisiones de emprender cambios en la universidad. El Consejo Universitario se preocupó por dichos, contradicciones, retractaciones y tergiversaciones, amenazas y decisiones compulsivas, represivas y disciplinarias, no de temas del campo conceptual y de propuestas de mejoramiento del trabajo universitario. Vale decir, su visión no era de mediano ni largo alcance, sino de actuación frente a hechos rutinarios y de enfrentamiento con los estudiantes. Le faltó tino para afrontar el conflicto.

\section{Curiosa fórmula del Rector: la pena legal es enmienda, la perturbación no}

Mientras los alumnos se encontraban en huelga -conforme lo habían acordado-, las comunicaciones entre rector y ministro continuaron. Este le informó (3 de diciembre) que había recibido a dos alumnos comisionados por sus compa-

44 Revista Universitaria, Ibid., 57. 
ñeros para pedirle interponga sus buenos oficios para evitar la pérdida del año de estudios y acaso de su carrera. Y le impetró al rector que, en acto de benevolencia, y sin romper el rigorismo disciplinario, dé oportunidad a los alumnos para la rehabilitación de sus impulsos no meditados. Oficios y telegramas entre ambos prosiguieron hasta el término del año, con evidentes discrepancias. Mediante una de dichas comunicaciones, el ministro le dijo al rector que no se había seguido el procedimiento dispuesto por la ley de instrucción para aplicar la pena de expulsión: debe ser impuesta por las facultades, ejecutada por los decanos y revisada por el Consejo Universitario. Por tanto, este órgano gubernativo cerró todo recurso de revisión.

Pero el Consejo Universitario (21 de diciembre), por unanimidad de votos, discrepó con el ministro, alegando haber procedido con sujeción a la ley. Sin embargo, la universidad se regía internamente por un reglamento de 1908, desfasado en relación con la ley de instrucción de 1920. El consejo y el rector prosiguieron usando los términos de acuerdos y comunicaciones anteriores. En efecto, el rector expresó al ministro que los estudiantes habían desacatado a dicho órgano directriz y sus miembros fueron extrañados, condenados, injuriados, escarnecidos públicamente y amenazados con actos de violencia, y uno de ellos ultrajado de hecho. (Lo cual fue desmentido por el presunto ultrajado). Por ende, su respetabilidad sufriría desmedro, si no pudiera defenderla sin vacilación ni tregua. Además del presunto basamento legal, le dice al ministro que los procedimientos del consejo cuentan con la aprobación de casi todo el cuerpo de catedráticos.

Efectivamente, en aquel año, la Universidad de la Libertad tenía 16 docentes; de los cuales siete conformaban el Consejo Universitario: Carlos E. Uceda (rector), Francisco Quiroz Vega (vicerrector), Alejand ro Morales, Ricardo Rivadeneira, José M. Fernández, Eleázar Boloña e Ignacio Meave Seminario (secretario). De ellos, seis participaban uniformemente de los acuerdos del consejo. Un grupo de otros seis catedráticos se adhirió a la labor del rector y del mencionado órgano de gobierno a favor del mantenimiento del orden y la disciplina: Pedro A. Lizarzaburu, Santiago E. Uceda (hermano del rector), Julio E. Mannucci, Carlos Vega y Sanabria, Víctor Alejandro Hernández y Enrique L. Albrecht. En total, doce estuvieron de acuerdo con la pena de expulsión. En contra dos: Carlos C. Godoy y Saniel Chávarri, ambos de la Facultad de Filosofía, Historia y Letras. Y dos se excusaron de intervenir por vínculos familiares: Eleázar Boloña y Cecilio Cox, parientes del alumno Carlos M. Cox. En resumen: 12 estuvieron por la pena aplicada, dos en contra y dos se abstuvieron.

Así, pues, aduciendo razones legales, unidas a cuestiones de orden y disciplina, el Consejo Universitario y el rector negaron las peticiones del ministro para solucionar el problema.

Pero no solo eso. Hubo otros rechazos. El decano de la Facultad de Ciencias Jurídicas y Sociales de la Universidad de La Plata, Argentina, Dr. Alfredo L. Palacios, mediante comunicación fechada el 8 de febrero de 1924, atendiendo el pedido de uno de los interesados, se dirigió al rector para interponer su "anhelo de concordia y fraternal armonía en pro de los estudiantes expulsados". 
En su oficio manifestó su afecto a nuestro país como a una segunda patria, su admiración y gratitud al pueblo peruano y a su juventud que lo había honrado con el título elevado de Maestro, razones por las cuales se sentía autorizado y obligado a solicitar se derogue la medida disciplinaria. Aunque su petición podría ser desfavorablemente interpretada, dijo que solo le inspiraba el interés en el porvenir de los estudiantes, gravemente afectado por un probable arrebato juvenil. Y que no juzgaba los hechos, ni se parcializaba con un bando, tampoco discutía lo justificado o no de la medida, "pero invocando el dolor y los amargos quebrantos que ella habrá ya producido", se tomaba la libertad de solicitar el levantamiento de la pena. "Únicamente me atrevo -escribe- a demandarle que ejerciendo la clemencia, el atributo más alto de la justicia, impida que cristalicen en el alma siempre pura y generosa de la juventud, sedimentos amargos de discordia, fuente germinadora de futuros y perdurables enconos" ${ }^{\prime 5}$. Palacios había visitado nuestro país el año de 1919; en Lima recibió cálidas manifestaciones de aprecio por parte de los estudiantes universitarios.

El rector le respondió, con acuerdo del Consejo Universitario, del 2 de abril, que de la historia de los sucesos se desprenden dos cosas: a) no ha habido un movimiento ideológico de renovación y de mejora; tampoco una cruzada contra métodos docentes arcaicos, iniciada por los alumnos; b) los alumnos expulsados (en forma definitiva 14, y temporal 8), dominados por su extravío, solo consiguieron obcecación y escándalo, al desacatar a las autoridades, injuriar, escarnecer, amenazar y hasta ultrajar a uno de los profesores. Por tanto, la medida debía surtir todos sus efectos en obsequio de la autoridad del consejo, al decoro de los docentes, y al orden y la disciplina de la universidad.

Las autoridades insistían en que los estudiantes no han protagonizado movimiento alguno de ideas renovadoras, ni una campaña para mejorar los métodos didácticos caducos. Sin embargo, como ya está anotado en páginas precedentes, los estudiantes sí expusieron planteamientos sobre temas educativos y administrativos, aunque no los desarrollaron. $\mathrm{Y}$ al contrario, sus profesores, redujeron sus intervenciones a hablar de la subversión del orden y la disciplina por los alumnos. Frente a los hechos, ningún profesor propuso ideas de cambio.

Y desde Cajamarca, la Sociedad "Auxilio Mutuo Obrero" comunicó al rector (8 de febrero) que sus asociados, por unanimidad, aprobaron una moción sobre los sucesos universitarios de Trujillo. En uno de los considerando decía la moción "Que la solidaridad entre el elemento obrero y el elemento intelectual de la nación peruana, es ahora una hermosa realidad en pro de los verdaderos intereses progresistas de la patria, solidaridad que debe fomentarse por todos los medios". Esa solidaridad -añade- se ha menoscabado con los incidentes ocurridos en la Universidad de La Libertad entre docentes y alumnos. En su principal acuerdo dicha moción impetra del personal docente que, con motivo de la celebración del centenario de la fundación de esta institución, permita el reingreso a sus aulas, de todos los jóvenes separados de su seno. Los trabajadores cajamar-

45 Revista Universitaria, Ibid., 64-65. 
quinos también acordaron transcribir su moción a las instituciones obreras de Trujillo para que cooperen a su mejor éxito. El oficio es firmado por J. Enríquez, y la moción por los socios de la mencionada sociedad ${ }^{46}$.

Como en todos los casos anteriores, el Consejo Universitario y el rector no accedieron a esta solicitud. El Consejo Universitario acordó el 2 de abril de 1924 denegar las solicitudes de Palacios y de la Sociedad de Auxilio Mutuo Obrero de Cajamarca, y aprobó los oficios de respuesta del rector. De este modo, las razones son las mismas dadas al ministro de instrucción y al doctor Palacios: la sanción infligida debe surtir todos sus efectos para imponer el orden y la disciplina, frenar los desmanes, prevenir de modo "saludable" a los demás alumnos y mantener el imperio inexorable de la norma. Además, dice el rector que la solidaridad se ha roto por las faltas graves cometidas por los alumnos, no por la aplicación de la pena. Y aquí aparece un elemento nuevo expresamente escrito por el rector: "La pena legal es enmienda, mas no perturbación" 47.

Esta idea ha estado presente, en forma tácita, desde la aplicación de las primeras medidas disciplinarias, pero ahora aparece formulada en el papel, expresamente. Las autoridades están convencidas de que toda disposición legal es correcta, positiva, justa, por ende, sirve para enmendar errores; y, por el contrario, todo acto de "perturbación" no conduce a una corrección o superación de deficiencias. Obviamente, la ley se debe cumplir, pero eso no significa que siempre la ley sea la norma más adecuada y justa. Esto, seguro, lo sabían los catedráticos por solo su condición de tales, pero con mayor razón, en el caso de la mayoría de ellos, por su profesión de abogados. Y en cuanto a que los hechos perturbadores no enmiendan o corrigen, su desmentido se lo encuentra en la historia de las revoluciones por medios de las cuales se trastoca o altera el orden social y se rompen las cadenas de opresión para alcanzar la libertad de hombres y pueblos. El propio movimiento estudiantil de Reforma Universitaria es un ejemplo de ello. Algo más, a veces, las sanciones legales, por injustas, lejos de enmendar, son causales de conflictos, perturban el comportamiento individual y colectivo. $\mathrm{Y}$ hay sanciones que no son legales pero enmiendan, como sucede con las sanciones morales.

Pretendiendo justificar ante el público su actitud en el conflicto con los alumnos, el rector disponía la publicación de las actas del Consejo Universitario, en diarios locales. El análisis de dichos documentos llevó a Antenor Orrego a emitir nuevamente su opinión en editorial de El Norte que condensa este proceso. Allí escribió: "El alumnado afirma un gesto generoso, el profesorado lo elude. El uno reacciona en forma positiva y por lo tanto, creadora, ante una realidad nacional; el otro, haciendo penosos y trabajosos esfuerzos legalistas, quiere mantenerse en una actitud negativa. El uno, proclama derechos; el otro, hace degenerar el objetivo principal en una cuestión disciplinaria. El uno, afirma hechos; el otro, esgrime reglamentos. En el gesto del uno, hay elaboración mental y ética; en el gesto del otro, hay elaboración de pura secretaría. Los alumnos hacen el rol de ciudadanos; los catedráticos de burócratas" 48 .

Los jóvenes universitarios, por intermedio de la FEP, gremios de trabajadores y la opinión pública de Trujillo, condenaron y rechazaron la medida de las auto-

\footnotetext{
46 Revista Universitaria, Ibíd., 67-68.

47 Revista Universitaria, Ibíd., 66 y 69.

48 Antenor Orrego, Obras completas Tomo II, op. cit., 258-259. Antes, "El conflicto universitario", en El Norte, 1930, en el cual su autor transcribe el editorial de 1923 del mismo periódico acerca de los sucesos universitarios de entonces.
} 
ridades académicas. La revista Claridad, desde Lima, alzó su enérgica protesta. Se lee en unos pasajes de su comentario: "La juventud libre del Perú presenció con verdadero estupor la realización por la docencia de la Universidad de Trujillo de un acto de un reaccionarismo insólito que merece la condenación de todas las conciencias libres del país y de América". "La juventud universitaria de Trujillo es quizá el núcleo juvenil que ha tenido en el país el año pasado -dice la nota de 1924- la agitación idealista más intensa" ${ }^{49}$.

Por la tozudez del Consejo Universitario, ningún argumento a favor de los alumnos fue válido. Sacrificó a 22 alumnos, 14 de ellos no regresaron a las aulas de la Universidad de La Libertad. Pero algunos de ellos, prosiguieron sus estudios en otras universidades, se graduaron y alcanzaron notabilidad en sus profesiones y en el quehacer político, por ejemplo: Carlos Manuel Cox y Luciano Castillo fueron catedráticos de San Marcos y miembros del Congreso de la República por agrupaciones partidarias diferentes; Edmundo Haya de la Torre, reconocido jurista. Y entre los expulsados temporalmente, el poeta Eloy Espinoza, muchos años después, alcanzó la cátedra universitaria en el campo del derecho en su propia alma mater.

\section{CONCLUSIÓN}

Las actitudes e ideas de los estudiantes trujillanos ponen de manifiesto que la Reforma Universitaria en América Latina fue un movimiento unitario y que los sucesos en los diversos lugares y años no son más que momentos de un solo proceso general. Los conceptos de universidad de puertas abiertas, porque son casas del pueblo y para el pueblo, se escucharon por doquier, como también que la universidad no la conforman solamente los catedráticos, sino también los alumnos y, por ende, cuando estos celebran reuniones dentro de los ambientes de su casa de estudios, no es una concesión de las autoridades sino un derecho.

El rector y los catedráticos, primero, en solidaridad con los estudiantes de la Universidad de San Marcos, condenaron el autoritarismo gubernamental; después, se enfrentaron a sus propios alumnos que abrazaron una posición principista frente a los mismos hechos.

Mientras las autoridades académicas y los catedráticos exhiben ideas anacrónicas, respecto a la vida universitaria, los estudiantes y sus delegados, igualmente los egresados, se ubican en la postura de una educación para el cambio.

En Trujillo, como en todo el Perú y el espacio latinoamericano, el movimiento estudiantil de reforma, no se circunscribió únicamente a los lindes académicos, sino tuvo relación con el campo social, particularmente con los trabajadores manuales.

La expulsión definitiva de un grupo de estudiantes y parcial de otros fue una decisión de tipo compulsivo, no formativo, propia de un cuartel, no de una academia. Aun suponiendo que el Consejo Universitario hubiese tenido la razón -lo cual no se deduce de la documentación consultada- la separación de estudiantes para imponer el orden y la disciplina -como lo sostenían el rector y los catedráticos- no era la mejor forma de lograr su cometido, precisamente porque el indisciplinado es el

49 Historia del conflicto universitario de Trujillo, Claridad. Órgano de la Federación Obrera Local de Lima y de la Juventud Libre del Perú, año I, No. 5, (1924):16-17. 
que requiere mayor atención por parte de sus profesores, para cuyo objeto debieran permanecer en las aulas.

Cuando el rector considera que "la pena legal", vale decir, la expulsión de los estudiantes, conduce a enmendar errores, no así la "perturbación", esto es el reclamo, la protesta, la insurgencia, está errado. La autoridad parte del falso supuesto de que toda norma legal es justa y conduce a la corrección; en cambio el acto de trastocar el orden (educativo, social u otro) no conduce a la enmienda. Esto lo desmiente la historia de las revoluciones constructivas con las cuales los pueblos lograron libertad y justicia. Y el propio movimiento reformista universitario que condujo a innegables cambios en las casas de estudios superiores.

\section{FUENTES}

Honorable Concejo Provincial de Trujillo. Acta de sesiones 1923-1925, tomo 56.

Libro de Actas de Sesiones del Consejo Universitario. Universidad Nacional de Trujillo, 1915-1931.

Documentos relativos a los últimos sucesos universitarios, Revista Universitaria. Órgano de la Universidad de La Libertad. Año 2-№ 5. Trujillo, enero-abril de 1924.

Sesión extraordinaria del Consejo Universitario celebrada el 9 de octubre de 1923, Universidad de Trujillo.

Sesión extraordinaria del Consejo Universitario celebrada el 9 de octubre de 1923, Universidad de Trujillo.

Sesión extraordinaria del Consejo Universitario celebrada el 9 de octubre de 1923, Universidad de Trujillo.

Sesión extraordinaria del Consejo Universitario celebrada el 14 de octubre de 1923, Universidad de Trujillo.

Sesión extraordinaria del Consejo Universitario celebrada el 19 de octubre de 1923, Universidad de Trujillo.

Sesión del Consejo Universitario celebrada el 2 de noviembre de 1923, Universidad de Trujillo.

Sesión ordinaria del Consejo Universitario celebrada el 15 de noviembre de 1923, Universidad de Trujillo.

Sesión extraordinaria del Consejo Universitario celebrada el 20 de noviembre de 1923, Universidad de Trujillo.

-Decisiones estudiantiles:

Acuerdo de 25 alumnos tomados el 10 de octubre en un salón de la universidad.

Acuerdos de los estudiantes universitarios.

Memorial de los alumnos a los catedráticos. Nombre del archivo o fuente donde se obtuvo

-Comunicaciones cambiadas entre el señor Ministro de Instrucción y el señor Rector de la Universidad de La Libertad sobre los sucesos anteriores.

-Comunicaciones cambiadas con el señor doctor Alfredo Palacios y el señor presidente de la Sociedad "Auxilio Mutuo de Cajamarca".

Revista Claridad. Órgano de la Federación Obrera Local de Lima y de la Juventud Libre del Perú. Año I, No. 5, 2ª quincena de marzo de 1924: Historia del conflicto universitario de Trujillo.

\section{REFERENCIAS}

Basadre, Jorge. Perú: Problema y posibilidad. Lima: Banco Internacional del Perú, 1978.

Castillo, Luciano y Salomé Díaz (1923). “El gallardo mensaje de la juventud universitaria de Trujillo a Vasconcelos", Claridad. Organo de la Juventud Libre del Perú. Año 1, no. 3, Lima, 2a quincena de septiembre de 1923.

Cossío del Pomar, Felipe. Víctor Raúl. Biografía de Haya de la Torre. México: Editorial Cultura, 1961. 
Del Mazo, Gabriel (1967). Gabriel Del Mazo, “Memorial de la Federación Universitaria al Ministro de Instrucción Pública fundamentando su pedido de intervención a los fines de la reforma institucional y reorganización de la Universidad. La Plata, 26 de noviembre de 1919" en La Reforma Universitaria Tomo II. Lima: Universidad Nacional Mayor de San Marcos, 1968, 112.

González R., Eugenio y otros. "Los ideales de la revolución universitaria en Chile”. En La Reforma Universitaria Tomo II, editado por Centro de Estudiantes de Ingeniería (La Plata: 1968

Haya de la Torre, Víctor Raúl. Obras completas Tomo I. Lima, Librería-Editorial Juan Mejía Baca, 1977.

Haya de la Torre, Víctor Raúl. "Carta desde la prisión". En Por la emancipación de América Latina, editado por M. Gleizer (Buenos Aires: Triunvirato, 1927).

Haya de la Torre, Víctor Raúl. Obras completas Tomo II. (Lima, Librería-Editorial Juan Mejía Baca, 1977.

Haya de la Torre, Víctor Raúl. "Autobiográfica". En ¿A dónde va Indoamérica? Buenos Aires: Editorial Ercilla, 1935.

Herrera, Fortunato, José Gabriel Cossío, Luis E. Valcárcel, Uriel García, Leandro Pareja y Alberto Araníbar. "Bases para reformar la Universidad del Cuzco. Ante Proyecto de un Nuevo Estatuto Universitario". Amauta, Año II, no. 10, (1927).

Mariátegui, José Carlos. "Arte, revolución y decadencia". Amauta, Año I, No. 3, (1926).

Mariátegui, José Carlos. 7 ensayos de interpretación de la realidad peruana. Lima: Editora Amauta, 1959.

Mariátegui, José Carlos. Temas de educación. Lima: Empresa Editora Amauta, 1970.

Martínez Durand, Carlos. "La Reforma Universitaria en Guatemala". En: Reforma Universitaria Tomo II. Lima: Universidad Nacional Mayor de San Marcos, 1968.

Mesplé, Juan A. "La Reforma Universitaria en Río Grande del Sur". En Reforma Universitaria Tomo II. Lima: Universidad Nacional Mayor de San Marcos, 1968.

Molina Bravo, José. "Educación pública, autonomía universitaria y cambio político: Notas para el análisis del movimiento universitario en Chile, 2011". Revista Historia de la Educación Latinoamericana. Vol. 15 No, 21, (2013): 263 - 282.

Orrego, Antenor. Memoria del Sr. Dr. Don Antenor Orrego rector de la Universidad Nacional de Trujillo leída el día de la apertura del presente año académico. Trujillo: Librería e Imprenta Moreno, 1947.

Orrego, Antenor. Obras completas Tomo I. Lima: Editorial Pachacutec, 2011.

Orrego, Antenor (2011). Obras completas Tomo II. Lima: Editorial Pachacutec, 2011.

Robles Ortiz, Elmer. La Reforma Universitaria: Sus principales manifestaciones. Trujillo: Fondo Editorial de la Universidad Privada Antenor Orrego, 2009.

Stein, Steve. “El APRA, los años de formación”, en Histórica VI, No. 1, (1982).

Vasconcelos, José. Mensaje de Vasconcelos a los estudiantes peruanos. Juventud. Revista de los Estudiantes Renovadores de la Universidad de La Habana Tomo I, año I, No. VII-VIII, (1924).

Benito Rodríguez, José Antonio. Emilio Lissón Chávez. José Antonio Benito Rodríguez, Emilio Lissón Chávez. Diccionario Enciclopédico de Biblia y Teología, 2016) http://www.biblia.work/diccionarios/emilio-lisson-chavez/ (9/07/2016).

\begin{tabular}{l|l|} 
& \\
\hline $\begin{array}{l}\text { Robles Ortiz, Elmer. “Repercusiones en Trujillo de los sucesos } \\
\text { estudiantiles de Lima el } 23 \text { de mayo de 1923". Revista Historia de la } \\
\text { Educación Latinoamericana. Vol. } 20 \text { No. } 30 \text { (2018): 85-122 }\end{array}$ & \\
\hline &
\end{tabular}




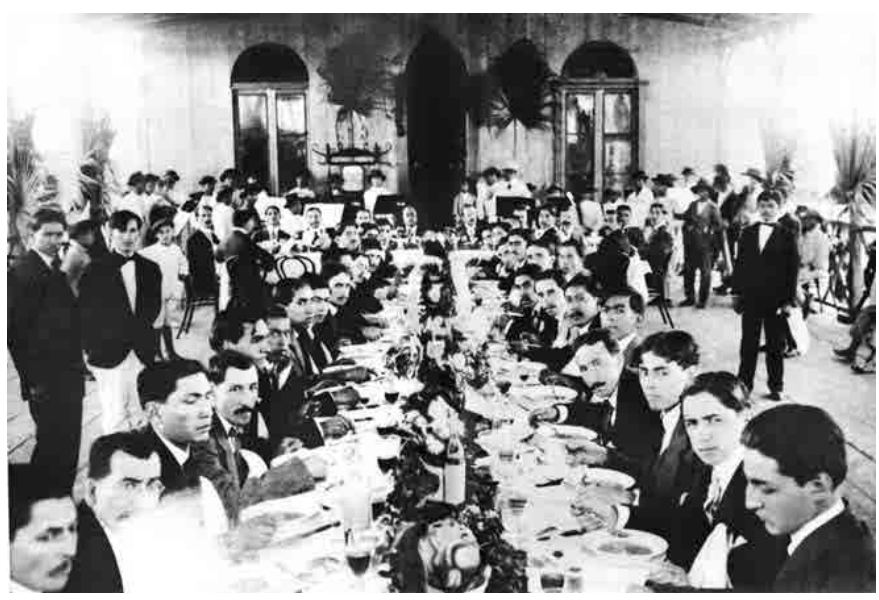

Grupo Norte, otros estudiantes, catedráticos y autoridades de la UNT. Ágape en el restaurante Morillas, 1916. A la izquierda, primero Víctor Raúl Haya de la Torre,cuarto Antenor Orrego,séptimo Oscar Imaña,décimo Carlos Manuel Cox; a la izquierda, quinto César Vallejo, sexto Federico Esquerre 